\title{
Output Effects of Government Purchases
}

\section{Citation}

Barro, Robert J. 1981. Output effects of government purchases. Journal of Political Economy 89(6): 1086-1121.

\section{Published Version}

doi:10.1086/261024

\section{Permanent link}

http://nrs.harvard.edu/urn-3:HUL.InstRepos:3451294

\section{Terms of Use}

This article was downloaded from Harvard University's DASH repository, and is made available under the terms and conditions applicable to Other Posted Material, as set forth at http:// nrs.harvard.edu/urn-3:HUL.InstRepos:dash.current.terms-of-use\#LAA

\section{Share Your Story}

The Harvard community has made this article openly available.

Please share how this access benefits you. Submit a story.

Accessibility 


\title{
Output Effects of Government Purchases
}

\author{
Robert J. Barro
}

University of Rochester and National Bureau of Economic Research

\begin{abstract}
The theoretical analysis focuses on the distinction between temporary and permanent movements in government purchases. Under plausible conditions, the temporary case involves an output response that is positive, less than one-to-one with the change in government purchases, and larger than that generated by an equal-sized, but permanent, shift in purchases. The equilibrium real rate of return rises in the temporary case, but changes little in the permanent one. Defense purchases are divided empirically into "permanent" and "temporary" components by considering the role of (temporary) wars. No temporary shifts in nondefense purchases were isolated. Empirical results verify an expansionary output effect for temporary purchases that exceeds that of permanent purchases. The results for some other expectational hypotheses are found to be generally supportive of the theory.
\end{abstract}

Macroeconomic analysis typically assigns government purchases an important role in influencing aggregate demand and thereby in affecting output and employment. Bailey (1971) points out that these expansionary effects are offset to the extent that governmentally provided goods and services are close substitutes for private consumption expenditures. Hall (1980) argues that temporary changes in government purchases can have a substantial business cycle role, because they stimulate intertemporal substitution of work and pro-

This research is supported by the National Science Foundation. Earlier versions of this paper were presented at the Charles Haywood Murphy Symposium on Government Debt, Fiscal Policy, and Expectational Theory at Tulane University, October 1979, and at seminars at Columbia, Harvard, the University of Florida, and Stanford. I have benefited especially from comments by Jeremy Bulow, Stan Engerman, Ben Friedman, Donald Hester, Bob King, Levis Kochin, Yoram Peles, and Charles Plosser, and from the research assistance of Louis Chan, Gary Gorton, and Chitra Ramaswami. 
duction. These effects are most important in the case of transitory expenditures that are not close substitutes for private spendingnotably for wartime spending-but would not apply to long-run changes in government purchases. Public services also play a role as an input (perhaps usually with positive marginal product) into private production processes. This characteristic provides a direct channel whereby shifts in government purchases can alter the level of total output.

The present analysis focuses on the theoretical and empirical distinction between temporary and permanent variations in government purchases. A simple theoretical framework is used to analyze the output and real-rate-of-return effects of these purchases. It is argued first that movements in the real rate of interest arise mainly when government purchases are temporarily high or low and, second, that the response of output is likely to be larger when the change in purchases is temporary rather than permanent.

The empirical section estimates the division of defense purchases into permanent and temporary components by considering the effects of war and of war expectations. Defense spending associated with wars is largely transitory, while other changes in defense spending turn out to be predominantly permanent. Shifts in nondefense federal plus state and local purchases are also mostly permanent in character.

Analysis of real GNP reveals a significant expansionary effect of temporary defense purchases. Permanent defense purchases have a significantly weaker, but still significantly positive, effect on real GNP. The coefficient associated with permanent nondefense purchases is imprecisely determined, which prevents concluding either that these output effects are nonzero or that they differ significantly from those produced by permanent defense spending. Because no temporary changes in nondefense purchases were isolated, it was not possible to determine the output effects from this category of purchases. Some more detailed hypotheses that concern the generation of expected long-run average defense purchases are formulated, tested, and accepted. Finally, the determination of real GNP during World War II is analyzed and compared with relationships for the postwar period.

\section{Theoretical Considerations}

\section{Setup of the Model}

This section constructs a simple theoretical framework, which is used to study the effects of government purchases on output and the real rate of interest. The setting is designed to focus on the distinction 
between temporary and permanent movements in government purchases.

Suppose that the economy-wide credit market establishes an anticipated real rate of interest on loans, which is denoted by $r$. For simplicity, economic agents are assumed to act as if $r$ were constant over time. The model can be extended to permit (valid) expectations in some circumstances of divergences between current and anticipated future values of $r$ (see below).

An increase in $r$ motivates the postponement of consumption and leisure from the present to the future. Therefore, $r$ has a negative effect on consumption demand, $C^{d}$, and a positive effect on the supply of labor services. ${ }^{1}$ The positive effect on labor supply impliesthrough the equilibration of a labor market that is not considered explicitly - a positive effect of $r$ on commodity supply, $Y^{s}$. For present purposes, it is satisfactory to ignore the intervening factor markets and view households and producers as integrated economic units. In this case, the rise in $r$ directly boosts current supplies of goods and services. A higher value of $r$ tends also to deter the accumulation of capital. However, in order to simplify matters, the discussion of investment effects is limited to footnotes in the subsequent analysis.

\section{The Government's Budget}

The government's real demand for commodities during period $t$ is denoted by $G_{t}$. Let $T_{t}$ represent the real value of date $t$ 's tax collections, net of any transfer payments. Taxes and transfers are treated initially as lump sum in nature, but this assumption is relaxed later. Inflationary finance can be viewed as a particular form of (non-lumpsum) tax, which need not be introduced separately for present purposes. The model does not deal with monetary variables or the determination of the absolute price level and the nominal interest rate. These matters do not seem central for a study of the real effects of government purchases.

Abstracting initially from interest-bearing public debt, the government's budget constraint requires an equality each period between purchases and the net amount of real taxes:

$$
G_{t}=T_{t}
$$

The possibility of government borrowing relaxes this condition of budget balance each period, but does not alter the principal findings that are discussed below.

${ }^{1}$ A change in $r$ involves pure, unambiguous substitution effects if the underlying production technology is held fixed (see Bailey 1971, chap. 6). 
In calculating its permanent income, the representative household figures in the anticipated present value of its share of taxes-net-oftransfers. For aggregate purposes, the important magnitude at some starting date 0 is the expectation of the present value, $\sum_{t=1}^{\infty}\left[T_{t} /(1+r)^{t}\right]$. From equation (1), this magnitude coincides with the expected present value of government purchases, $\sum_{t=1}^{\infty}\left[G_{t} /(1+r)^{t}\right] .^{2}$ It is convenient to work with the uniform flow of purchases, $\bar{G}$, that would yield the same present value of purchases as the time path, $G_{t}$. This flow, which is referred to as "permanent purchases," is determined from the condition

$$
\bar{G} \equiv r \sum_{t=1}^{\infty}\left[G_{t} /(1+r)^{t}\right] .
$$

Holding fixed any service value that the private sector attaches to the time path of $G_{t}$-which is discussed next-a rise in $\bar{G}$ impacts on households exactly as would a corresponding decrease in permanent income. In particular, an increase in permanent purchases, $\bar{G}$, tends to reduce $C^{d}$ and raise the supply of labor services at all dates. (The positive response of work effort depends on the lump-sum nature of taxes. See the subsequent discussion.) The increase in work offers translates-through the equilibration of the labor market or via the direct behavior of household/producers in the present framework-into increased commodity supply, $Y^{s}$.

For a given value of $r$, a rise in $\bar{G}$ requires a one-to-one decline in the representative household/producer's "average" planned value over time for $C^{d}$ net of $Y^{s}$. This result follows from the intertemporal budget constraint for a household/producer, where the time path of $C^{d}$ and net real taxes appear on the expenditure side, and the time path of $Y^{s}$ appears on the income side. If the current value of $C^{d}$ net of $Y^{s}$ falls by less than one-to-one with $\bar{G}$, then the typical household must be planning to reduce some future net values by greater than one-to-one. That is, the household responds in this case to the drop in effective permanent income by shifting relative expenditures (on consumption and leisure) from the future to the present. Similarly, a decline in current values by more than one-to-one with $\bar{G}$ would signify an intention to shift expenditures from the present to the future. Since a pure income effect is involved, it seems reasonable to

\footnotetext{
${ }^{2}$ With public debt included, the expected present value of net real taxes equals the expected present value of real purchases plus the initial amount of real government debt. In particular, there is still a one-to-one relation between changes in the anticipated present values of real purchases and net real taxes. This calculation assumes that the government's real interest rate equals $r$. The possibility of chain-letter, perpetual deficit finance has also been excluded. See Barro (1978) for a discussion of these and related matters, including the role of finite lifetimes.
} 
concentrate on the intermediate case where the intertemporal pattern of expenditures is unchanged. In this case, at a given value of $r$, the decline in current $C^{d}$ net of the increase in $Y^{s}$ exactly matches the rise in $\bar{G}{ }^{3}$

\section{The Role of Public Services}

The government is viewed as utilizing its commodity purchases at each date, $G_{t}$, to provide a contemporaneous flow of public services to the private sector. These services are treated as provided free of charge to household/producers. Two types of services are considered. One form is modeled as a direct conveyer of utility to households. Examples which do not encompass the traditional roles of government include parks, libraries, school lunch programs, (subsidized) hospitals, and, possibly, highway and transportation programs. (The latter category could be viewed alternatively as an input to private production functions.) An important feature of these forms of public services is the possibility of close substitution with private consumer spending.

The second type of service is an input to private production processes, which can apply either to businesses or households. Examples include the provision of a legal system, aspects of national defense, fire and police services, education, and various regulatory activities. (The last item is likely to exhibit negative marginal product.) In some cases these services would be close substitutes for private inputs of labor and capital. However, in areas like the provision of a legal system and national defense, the public services are likely to enhance the marginal products of private factors.

In many situations a particular government activity would exhibit features of both general types of public services that are being considered. The extent to which each feature was represented would vary across a wide range of programs. Despite this real world diversity, the formal analysis proceeds as if there were a single type of governmental activity, which has service attributes that are partly of the direct-utility type and partly of the productive-input type.

Government-provided services are often modeled as "public," as opposed to private, goods in the sense of being "nonrival"-one person's enjoyment of the good does not diminish the enjoyment by another person. ${ }^{4}$ It is doubtful that this characteristic applies to the

\footnotetext{
${ }^{3}$ This result does not depend on an infinite horizon for the representative household. Finite lives can alter the effects of some government actions, such as changes in public debt or social security, that involve a publicly mandated shift in incomes across generations. Government purchases that are financed contemporaneously by taxes (which are independent of age) do not involve these considerations.

${ }^{4}$ This characteristic is embedded in the theoretical analysis of Samuelson (1954).
} 
majority of government purchases at the current time. Falling outside of this category would be the bulk of expenditures on education, hospitals, school lunch programs, and any service that is subject to congestion, such as parks, courts, libraries, transportation and highway projects, and police/fire services. Even in the case of national defense, the benefits to individuals are likely to be relative to the total amount of property that is being defended, because the level of external threat would respond to the potential prize from conquest (see Thompson 1974).

In a nonrivalry situation, individual utility or production would depend on the total of government services rather than on the quantity provided to the particular economic unit. Because nonrivalry seems atypical, the modeling assumes that individual utility and production depend on real government purchases per capita. However, the general form of the analysis would not be altered appreciably if some elements of nonrivalry were introduced.

Consider, first, the direct interplay in utility functions between government services and household choices of consumption and leisure. Suppose, as stressed by Bailey (1971, chap. 9), that the contemporaneous levels of (per capita) $G_{t}$ and (individual) $C_{t}$ are close substitutes in utility terms. For example, assume that each unit of $G_{t}$ (per capita) is viewed as providing utility services that are equivalent to a fraction $\theta$ of a unit of contemporaneous individual consumption expenditure. ${ }^{5}$ That is, household utility depends on the effective consumption flow at each date, $C_{t}^{*} \equiv C_{t}+\theta G_{t}$, where $0 \leqslant \theta \leqslant 1$. The formulation neglects this type of utility substitution among noncontemporaneous values for $C$ and $G$ or between $G$ and leisure. ${ }^{6}$ The provision of these types of public services means that households obtain units of effective consumption, $C^{*}$, that exceed the quantity of private real expenditures, $C$. The permanent flow of government purchases, $\bar{G}$, can be used to finance the uniform effective consumption flow, $\theta \bar{G} \cdot{ }^{7}$ This aspect of public services offsets the negative permanent income effect from $G$ that was described earlier (see also n. 6 above). The permanent income effect that is pertinent to private choices on consumption expenditure and leisure is now $(\theta-1) \bar{G}-$ the condition $0 \leqslant \theta \leqslant 1$ implies that the permanent income effect of $\bar{G}$ is still less than or equal to zero, but no larger than one in magnitude.

\footnotetext{
${ }^{5}$ The parameter $\theta$ can be viewed in the following analysis as applying to the marginal unit of $G_{t}$.

${ }^{6}$ The time path of $G_{t}$ could also affect overall household utility in a form that was additively separable from the time paths of effective consumption and leisure. In this sense the $\theta$ parameter need not limit the utility value that households attach to public services. This possibility does not invalidate the subsequent discussion of permanent income changes that are induced by shifts in $\bar{G}$.

${ }^{7}$ The discussion assumes that the inequality constraint, $C_{t} \geqslant 0$, is never binding.
} 
With $\bar{G}$ held fixed, an increase in $G_{t}$ now implies some direct crowding out of contemporaneous private commodity demand. In order to maintain the level of effective consumption, $C_{t}^{*}-$ which is appropriate when $\bar{G}$, the other determinants of permanent income, and $r$ are held fixed $-C_{t}^{d}$ must decline with $G_{t}$ in accordance with the parameter $\theta$. The greater the utility substitution (at the margin) between $C_{t}$ and $G_{t}$-as measured here by $\theta$-the larger the negative response of $C_{t}^{d}$ to an increase in $G_{t}$. As long as $\theta \leqslant 1$ applies, aggregate commodity demand for date $t-Y_{t}^{d} \equiv C_{t}^{d}+G_{t}$-rises as the nonnegative fraction, $(1-\theta)$, of increases in $G_{t}$ (when $\bar{G}$ is held fixed).

Consider next the role of public services as an input to private production processes. It is assumed that public services of this type have a positive marginal product, which is denoted by MPG. The condition MPG $\leqslant 1$, which is assumed to hold, implies that the marginal response of (aggregate) private output to an increase in (aggregate) $G$ does not exceed the social cost of providing the extra public services input. Through its role as a productive input, an increment in $G$ raises commodity supply, $Y^{s}$, for given levels of private factor inputs. Note that part of total output will be utilized to provide intermediate goods, which take the form of publicly supplied production inputs. Although there are good reasons in principle for deleting these intermediate goods from measures of final product, this approach is not followed in the national accounts. ${ }^{8}$ In the theoretical analysis the output measure, $Y$, is also gross of this type of intermediate production.

Because the public-service inputs are provided freely, a change in $G$ alters private sector real incomes in accordance with the marginal product, MPG. The representative household receives a per capita share of this extra real income. This effect further offsets the inverse influence of $\bar{G}$ on permanent income. The net effect now depends on the term $(\theta+$ MPG -1$)$, which is nonpositive but no greater than one in magnitude if $0 \leqslant \theta+$ MPG $\leqslant 1$ applies. $^{9}$

If variations in $G$ alter the marginal products of private productive inputs, then additional effects would arise through changes in factor demand functions. Cases where public services substitute for private inputs-such as the provision of public rather than private

${ }^{8}$ These matters are discussed in Kuznets (1948, pp. 156-57) and Musgrave (1959, pp. 186-88). The double-counting property for publicly provided production inputs implies that empirical counterparts of total output, like real GNP, overstate the response of final output to government purchases.

${ }^{9}$ Recall that the analysis deals with a composite government service that has attributes of the direct-utility $(\theta)$ and production-input (MPG) type. A particular category of purchases is unlikely to exhibit a high value for both parameters, $\theta$ and MPG. Therefore, if $\theta \leqslant 1$ and MPG $\leqslant 1$ apply for each category of purchases, the condition $\theta+$ MPG $\leqslant 1$ is likely to hold for the composite over all categories. 
guards-would generate reductions in the marginal product of labor. On this count, the private demand for labor would tend to fall when $G$ rises. In some other cases the private demand for capital services would decline. However, to the extent that background services like national defense and a legal system are expanded, factor marginal products are likely to rise, which would generate the opposite responses in private factor demands. The main analysis neglects the array of possible effects of government purchases on private factor marginal products.

\section{Commodity-Market Clearing}

The equilibrium condition for the commodity market is given by

$$
\begin{aligned}
& Y^{d} \equiv C^{d}(\ldots, r, \quad G, \bar{G})+G=Y^{s}(\ldots, r, \quad G, \bar{G}) . \\
& (-)(-)(-) \quad(+)(+)(+)
\end{aligned}
$$

Recall that the analysis has neglected the investment component of demand and has, thus far, assumed lump-sum taxation. Time subscripts have been omitted for convenience. Signs beneath the independent variables refer to partial derivatives. The omitted arguments in the $C^{d}$ and $Y^{s}$ functions involve various fixed aspects of households' permanent incomes, the production technology, and so on. As mentioned before, the real rate of return, $r$, exerts intertemporal substitution effects that are negative on $C^{d}$ and positive on $Y^{s}$. A rise in $G$ has a negative crowding-out effect on the contemporaneous choice of $C^{d}$. The impact of $G$ on $Y^{s}$ is nonnegative if MPG $\geqslant 0$. A rise in $\bar{G}$ reduces the pertinent measure of households' permanent incomes, as discussed before, which leads to a decrease in $C^{d}$ and a rise in $Y^{s}$.

\section{Effects of a Temporary Rise in Government Purchases}

Consider a temporary expansion of real government purchases, where $G$ rises while $\bar{G}$ is held fixed. The budget condition from equation (1) implies that these purchases are financed by a contemporaneous increase in real taxes-net-of-transfers, $T$. In fact, for the context of a temporary rise in government spending-which is most pronounced at the federal level during wartime-it is more natural that the bulk of contemporaneous finance would take the form of interest-bearing debt issue rather than tax increases. This behavior allows the government to spread the higher taxes necessitated by temporary spending over a large time interval instead of implementing exceptionally high tax collections for a few periods (see Barro $[1979,1980 b]$ for discussions). With $\bar{G}$ held fixed, it would be possible to utilize interest-bearing debt so as to maintain the entire initial time 
path of net real tax collections, $T_{t}$. In any event, for the setting of lump-sum taxes, the present value of tax obligations is not altered by shifts between public debt and taxes (see n. 2 above). Since households' calculations of permanent incomes depend only on this present-value magnitude, the effects of increases in government purchases that are financed by debt issue would coincide with the effects of those that are financed by higher taxes.

The rise in $G$ reduces $C^{d}$ on the left side of equation (3) in accordance with the utility substitution parameter, $\theta$. Therefore, aggregate demand, $Y^{d}$, rises on net by $(1-\theta)$ times the increase in $G$. If the marginal product of public services, MPG, is positive, $Y^{s}$ rises with $G$ on the right side of equation (3). Overall, the shift in "excess demand," $Y^{d}-Y^{s}$, is determined by the term $(1-\theta-$ MPG). It was already assumed that this term is nonnegative-that is, the direct, one-to-one effect of $G$ on aggregate demand is offset only partially by the utility-substitution and productive-input aspects of government purchases.

Since an increase in $G$ raises excess commodity demand, a rise in the real rate of return is required in order to restore commodity-market clearing. ${ }^{10}$ This response in $r$ reduces $C^{d}$ and raises $Y^{s}$. The rise in $Y^{s}$ reflects the substitution of current work effort for planned future effort. Since $Y^{s}$ was also increased directly by the rise in $G$, it is apparent that equilibrium output rises. This output effect is greater the smaller is the value of $\theta$, the larger is the value of MPG, and the greater is the real interest rate elasticity of $Y^{s}$ relative to that of $C^{d}$. In the polar case where $\theta=1$ and MPG $=0$, the response of $Y$ and $r$ to $G$ would be nil. In this circumstance, government purchases would amount to lump-sum transfers to households, because $G_{t}$ and $C_{t}$ were perfect substitutes in the utility function.

Private consumer spending, $C^{d}$, is crowded out from the rise in $r$ and from the initial negative effect of $G$. Therefore, the positive response of $Y$ to $G$ must be less than one-to-one-that is, the model exhibits an output dampener rather than a multiplier.

The positive response of output to temporary movements in government purchases would apply especially to wartime periods. ${ }^{11}$ The higher real rate of return can be viewed as a price signal that induces the intertemporal substitution of resources toward periods such as wars in which aggregate output is valued unusually highly. This type

\footnotetext{
${ }^{10}$ Because the expansion of $G$ is temporary, the rise in the equilibrium real rate of interest would also be temporary. An extension to allow divergences between current and expected future real rates of return does not alter the basic analysis.

${ }^{11}$ Wartime may also be associated with uncertainties on maintaining property rights, which would tend to reduce private investment demand. The possibly changing probability of winning or losing a conflict would enter in this context. The analysis abstracts from these effects and from controls on prices or interest rates. Also excluded are effects of patriotism or coercive behavior, such as conscription.
} 
of substitution has been stressed by Hall (1980, Sec. 2), who points out also that this behavior differs in some important respects from the responses of supply to monetary misperceptions that occur in some business cycle theories that stress intertemporal substitution on the supply side (e.g., Lucas and Rapping 1969; Lucas 1975; Barro 1980a). The effect of temporary government purchases on the time arrangement of work and production does not rely on elements of misperception with respect to the general price level or other variables.

\section{Effects of a Permanent Rise in Government Purchases}

Suppose now that $G$ and $\bar{G}$ rise by equal amounts. The increase in $G$ was shown already to raise excess commodity demand in accordance with the term $(1-\theta-\mathrm{MPG})$. A higher value of $\bar{G}$ was shown earlier to reduce effective permanent income by the same factor. It was also noted above that the typical or intermediate response of $C^{d}$ net of $Y^{s}$ would be one-to-one with this type of change in effective permanent income. (This response arises when households reduce expenditures on consumption and leisure by the same amount in each period.) In this case the response of $\left(C^{d}-Y^{s}\right)$ equals $-(1-\theta-$ MPG) times the change in $\bar{G}$. Since this response exactly offsets the excess demand effect of $G$, the overall response in $\left(Y^{d}-Y^{s}\right)$ would be zero. It follows in this case that the real rate of interest is invariant with permanent changes in government purchases (under lump-sum taxation). ${ }^{12} \mathrm{Al}$ though the invariance of $r$ would not hold in general, this conclusion for an intermediate case contrasts with the presumption of a positive effect for the setting of a temporary increase in government purchases.

When $r$ is unchanged, it follows from equation (3) that consumption falls, and total output rises. The expansion of production reflects partly the direct effect of $G$ on $Y^{s}$ (which was assumed to be positive) and the negative income effect of $\bar{G}$ on leisure. (The net response of leisure becomes ambiguous when income taxation is introduced-see the subsequent analysis.) The decline in consumption means that output rises by less than one-to-one with the permanent expansion of government purchases; that is, an output dampener is again predicted.

\section{Non-Lump-Sum Taxation}

Some of the results are affected by the unrealistic assumption that government expenditures are financed by lump-sum taxation. This

\footnotetext{
${ }^{12}$ It follows also-assuming no direct effects on the marginal product of capital schedule-that capital accumulation would be unaltered.
} 
section explores the consequences of income taxes in a simple environment. Because the present analysis is concerned only with tax effects that are systematically related to changes in government purchases-rather than with public finance questions, per se-this simplified analysis may be adequate.

Suppose that government expenditures are financed by a general income tax. Let $\tau_{t}$ represent the effective tax rate on incomes that accrue during period $t .{ }^{13}$ In a nonproportional tax setup, $\tau_{t}$ would represent the average marginal income tax rate. Assume now that the government can borrow and lend at the real rate of interest, $r$ - the same rate that applies to the private sector. Given the permanent flow of real government spending, which includes $\bar{G}$ and the comparable measure for real transfers, ${ }^{14}$ and the possibility for variations in public debt, there exists some income tax rate $\bar{\tau}$ that is constant over time and also just satisfies the government's intertemporal budget constraint. ${ }^{15}$ Although many patterns of time-varying tax rates would also satisfy the government's budgetary requirements, it will be desirable in most circumstances ${ }^{16}$ _ in terms of minimizing the distortions that are imposed on the private economy - to stabilize income tax rates over time. That is, the government would adjust its public debt issues and redemptions in order to prevent divergences between current and expected future income tax rates. (For discussions of this type of result, see Barro [1979, 1980c]; Kydland and Prescott [1980, pp. 185-86].) In this setting changes in government purchases would not generate movements in current tax rates relative to expected future rates. This conclusion means that, first, variations in $G$ with $\bar{G}$ held fixed have no effect on tax rates; second, shifts in $\bar{G}$ imply equal changes in current and expected future tax rates, $\bar{\tau} ;{ }^{17}$ and third, for the purpose of studying government purchases, it is unnecessary to deal with the intertemporal substitution effects that would arise from expected time variations in income tax rates. ${ }^{18}$

Given this framework for tax rate determination, it is unnecessary to modify the main conclusions that were derived earlier for the case

\footnotetext{
${ }^{13}$ The analysis neglects the double taxation of incomes that flow through the corporate sector. Taxation in the form of inflationary finance could be included separately without affecting the main results.

${ }^{14}$ Real interest payments on an initial public debt stock would also enter.

1.5 Because changes in tax rates affect the tax base, $Y$, the solution for $\bar{\tau}$ is generally nonunique. However, the minimal possible value for $\bar{\tau}$ is the pertinent choice.

${ }^{16}$ It mav be optimal to allow tax rates to vary over the business cycle. A countercyclical pattern shows up empirically for the U.S. federal government. However, the pattern is at least less pronounced in terms of the total government sector.

${ }^{17} \mathrm{It}$ is assumed that increases in tax rates induce increases in real tax revenues within the relevant range.

${ }^{18}$ E.g., these types of effects are central to a study of the investment tax credit (see Kydland and Prescott 1977, pp. 482-86).
} 
of a temporary increase in government purchases. Notably, output and the real rate of interest continue to rise when $G$ increases, with $\bar{G}$ held fixed. The principal modification to the previous findings is that $r$ should be interpreted as the after-tax real rate of return, as calculated with the appropriate average marginal tax rate on interest income. ${ }^{19}$

For the case of a permanent increase in government purchases, the new element is the rise in the income tax rate, $\bar{\tau}$, along with the rise in $\bar{G}$ (see n. 17 above). The higher income tax rate motivates a shift away from market work and toward leisure and other nonmarket activities. In equation (3) this change is reflected as downward shifts in the $Y^{s}$ and $C^{d}$ functions. ${ }^{20}$ For given values of $r$ (now interpreted net of tax), $G, \bar{G}$, and so on, it is plausible that the declines in $C^{d}$ and $Y^{s}$ would roughly balance. In other words, as in some cases that were discussed earlier, there is no reason to expect a particular direction of change for the relative amounts of consumption and leisure expenditures that are conducted at different dates.

Given this pattern of response to a higher income tax rate, it still follows that a permanent shift in government purchases has no effect on the (after-tax) real rate of return. However, the negative effect of higher income taxation on the incentive to work offsets the tendency for output to rise. ${ }^{21}$ The net movement in output now involves three forces: first, the substitution away from work because of higher income tax rates; second, the negative income effect (associated with the higher level of $\bar{G}$ ) on leisure, which motivates more work; and third, the direct productive-input effect of $G$ on $Y^{s}$. The first two influences involve the standard ambiguous net response of leisure to the substitution and income effects that are generated by either a change in the real wage rate or a shift in the income tax rate that is applicable to labor income. However, the income effect here involves the term $-(1$ $-\theta-\mathrm{MPG}) \bar{G}$, while the tax shift applies one-to-one to $\bar{G}$. This difference increases the likelihood that the substitution effect will outweigh the income effect. Suppose that the substitution effect were, in fact, comparable to or dominant over the income effect. In this case the overall change in output that is induced by a permanent rise in

19 This result assumes that interest income is taxable and interest payments are deductible from taxable income. The conclusion neglects systematic differences between the marginal tax rates applicable to receivers of interest income vs. those pertinent for payers. The result is not affected directly by the taxation of nominal, rather than real, interest payments. However, other effects of inflation on effective tax rates would matter.

20 The incentive to accumulate capital would also be diminished. Through this channel, a permanent increase in government purchases tends to reduce the capital stock, even when the after-tax rate of return is unchanged.

${ }^{21}$ A reduction in the capital stock, as mentioned in $n .20$, reinforces this effect. 
government purchases would be bounded from above by the direct positive effect of $G$ on $Y^{s}$. This channel corresponds to only one portion of the positive output response that arose for the case of a temporary increase in government purchases-the other part involves the intertemporal substitution effect on work effort, which is associated with the increase in $r$. It follows that temporary rises in government purchases would induce larger output responses than equal size, but permanent, rises in purchases. The sign of the output response is now ambiguous for the case of a permanent expansion of government purchases-the reaction is more likely to be positive when the marginal product of public services is high.

Overall, temporary expansions of government purchases are distinguished from permanent increases in that, first, the positive effect on output of the temporary expansion is likely to be larger and, second, a positive effect on the (after-tax) real rate of interest is predicted only for the temporary case. The present empirical investigation deals only with output effects of temporary versus permanent movements in government purchases. Some preliminary analysis of real-rate-of-return effects is carried out in Barro (1981a).

\section{Empirical Implementation}

The theoretical propositions will be tested by examining the effects of government purchases in a reduced-form relationship for output, as measured by real GNP. The analysis is an extension of previous empirical research (Barro 1981b), which stressed the business cycle influences of monetary disturbances. This earlier work included a government purchases variable, but did not distinguish temporary from permanent government spending.

It is convenient to carry out the analysis in terms of the ratio of real government purchases to real GNP, $G / Y$. In particular, temporary or permanent variations in $G$ are assumed to enter relative to $Y$ in a linear relation for the $\log$ of output-that is,

$$
\log \left(Y_{t}\right)=\ldots+\beta_{1}[(G-\bar{G}) / Y]_{t}+\beta_{2}(\bar{G} / Y)_{t},
$$

where omitted variables indicated by . . include current and lagged monetary shocks and other deterministic and stochastic influences on output. The variable $\bar{G}_{t}$, which would generally be unobservable, is the permanent flow of government purchases as perceived at date $t$. The empirical procedure for handling this variable is discussed below. Lagged values of $G / Y$ and $\bar{G} / Y$ might also appear in equation (4), but these effects were not found to be important empirically.

The functional form in equation (4) implies that increments in 
government purchases induce increments in output in accordance with

$$
d Y\left[1+\beta_{1}(G-\bar{G}) / Y+\beta_{2} \bar{G} / Y\right]=\beta_{1} d(G-\bar{G})+\beta_{2} d \bar{G} .
$$

Therefore, in regions where $\left[\beta_{1}(G-\bar{G}) / Y+\beta_{2} \bar{G} / Y\right]$ is small relative to one, the coefficients $\beta_{1}$ and $\beta_{2}$ would indicate the approximate response of $Y$ to unit changes in $(G-\bar{G})$ and $\bar{G}$, respectively. The empirical results suggest that this approximation is satisfactory over the 1930-78 period in the United States, except for the World War II years.

The theoretical analysis suggests testing the hypothesis, $0 \leqslant \beta_{2} \leqslant \beta_{1}$ $\leqslant 1$. This restriction implies that temporary changes in government purchases have a larger output effect than permanent changes, but that permanent changes also raise (measured) real GNP. These conditions are likely, but not inevitable, implications of the theoretical model.

A central aspect of the empirical analysis is the representation for permanent real purchases as perceived at date $t, \bar{G}_{t}$. Suppose for the moment that the time-series behavior of $G_{t}$ implies a relationship for $(\bar{G} / Y)_{t}$ in terms of a set of parameters $\alpha$ and a vector of currently observed variables, $Z_{t}$ :

$$
(\bar{G} / Y)_{t}=F\left(Z_{t} ; \alpha\right) .
$$

In this case the unobservable construct, $\bar{G}_{t}$, could be substituted out from equation (4) to yield a relation for output in terms of observable variables and the vector of unknown coefficients $\left(\alpha, \beta_{1}, \beta_{2}\right)$,

$$
\log \left(Y_{t}\right)=\ldots+\beta_{1}\left[(G / Y)_{t}-F\left(Z_{t} ; \alpha\right)\right]+\beta_{2} F\left(Z_{t} ; \alpha\right) .
$$

Some hypotheses arise that concern the role of the $Z_{t}$ variables in equations (4), (6), and (7). If these variables can be guaranteed, ex ante, not to appear separately in the list of omitted elements that are denoted by . . in equation (4), then the $Z_{t}$ variables would appear in equation (7) only to the extent that they serve as determinants for $(\bar{G} / Y)_{t}$ in the $F$-function of equation (6). Some cross-equation restrictions therefore emerge for the parameters of equations (6) and (7).

The next sections deal with the problem of modeling a form of equation (6) for real government purchases in the United States. ${ }^{22}$

\footnotetext{
${ }^{22}$ Levis Kochin has suggested the attractive alternative of using the current overall tax rate as a proxy for the anticipated, long-run average ratio of government purchases to GNP. The rationale for identifying the current tax rate with the anticipated government expenditure ratio was discussed in the theoretical section. Some problems with implementing Kochin's suggestion are: First, the distinction between purchases and expenditures implies that a separate model would be required to predict future transfers (including interest payments), which is not obviously easier than modeling pur-
} 


\section{Government Purchases Equation}

The stress on transitory movements in government purchases suggests special attention to war-related expenditures, which are likely to be viewed as largely temporary. I have proceeded empirically by separating total government (federal plus state and local) real purchases of goods and services into a "defense" component, $G^{w}$, and other purchases, $G^{p}$. The present analysis does not attempt to classify components of government purchases in accordance either with their relative substitutabilities with private spending, as reflected above in the $\theta$ parameter, or with their role as inputs to private production, as measured above by the MPG parameter. Differences between defense and nondefense items with respect to these parameters affect the interpretation of some of the empirical findings. Presumably, defense purchases are characterized by a relatively low value of $\theta$ and possibly by a relatively high value of MPG. The former implies a relatively large output effect of temporary defense purchases, while the latter would enhance the output effects of both temporary and permanent defense purchases. The empirical analysis would be sharpened by obtaining a division of nondefense purchases into relatively homogeneous categories with respect to the $\theta$ and MPG parameters, but the feasibility of this classification is unclear. Transfer payments have not been included in the analysis.

\section{Defense Purchases}

A primary determinant of $G^{w}$ would be the level of current and anticipated future wartime activity, assuming that at least the timing of wars can be treated as exogenous with respect to expenditure decisions. I have quantified this influence by using a casualty rate measure $B_{t}$, which represents battle deaths per 1,000 total population (see table 1) for the wartime years since the Civil War: 1898, 1917-18, 1941-45, 1950-53, 1964-72. In effect, this variable can be viewed as an alternative to a set of wartime dummy variables. The casualty rate measure represents an attempt homogeneously to quantify the intensities of different wars and different years within each war, without using military expenditures or personnel measures, which are the types of variables that are to be explained. In particular, the use of

\footnotetext{
chases directly; and, second, the use of the tax rate to proxy the permanent expenditure ratio may work better for the federal government than for total government. See Benjamin and Kochin (1978), who argue that mobility possibilities would prevent state and local governments from choosing an excess-burden-minimizing debt policy. However, this issue involves also the federal government's interaction with state and local governments - that is, the federal government may compensate for public debt/tax variations that cannot be carried out at the state and local levels.
} 
TABLE 1

Casualty Rate Variable

\begin{tabular}{lllllllll}
\hline \hline Date & & $B$ & Date & & $B$ & Date & \multicolumn{1}{c}{$B$} \\
\hline 1898 & $\ldots \ldots$ & .0052 & 1945 & $\ldots \ldots$ & .603 & 1966 & $\ldots \ldots$ & .025 \\
1917 & $\ldots \ldots$ & $.23^{*}$ & 1950 & $\ldots \ldots$ & .071 & 1967 & $\ldots \ldots$ & .047 \\
1918 & $\ldots \ldots$ & $.28^{*}$ & 1951 & $\ldots \ldots$ & .097 & 1968 & $\ldots \ldots$ & .073 \\
1941 & $\ldots \ldots$ & .0044 & 1952 & $\ldots \ldots$ & .030 & 1969 & $\ldots \ldots$ & .046 \\
1942 & $\ldots \ldots$ & .162 & 1953 & $\ldots \ldots$ & .021 & 1970 & $\ldots \ldots$ & .021 \\
1943 & $\ldots \ldots$ & .205 & 1964 & $\ldots \ldots$ & .0014 & 1971 & $\ldots \ldots$ & .0067 \\
1944 & $\ldots \ldots$ & 1.090 & 1965 & $\ldots \ldots$ & .0070 & 1972 & $\ldots \ldots$ & .0014 \\
\hline
\end{tabular}

Sources._Vietnam (1964-72): Statistical Abstract of the United States, 1977, p. 369, table 590. World War I (1917-18) and Spanish American War (1898): Historical Statistics of the United States, 1975, p. 1140, line 880. Korean War (1950-53): relative yearly data from Department of the Army, Battle Casualties of the Army (1954), were applied to war total from Statistical Abstract of the United States, 1977, p. 369, table 589. World War II (1941-45): relative yearly data from Office of the Comptroller of the Army, Army Battle Casualties and Nonbattle Deaths in World War II: Final report, December 1941-December 1946, were applied to war total from Statistical Abstract of the United States, 1977, p. 369 , table 589. Korean War and World War II data were obtained from William Strobridge, Chief, Historical Services Division, Department of the Army.

Note. $-B$ is battle deaths per 1,000 total population. Values of zero apply to dates not listed. Orders-of-magnitude values of $B$ (per year) for earlier wars are: Revolution (1775-83), 0.2; War of 1812 (1812-15), 0.08; Mexican War (1846-48), 0.04; Civil War (1861-65, union only), 1.0. Casualty figures are from: Civil War: Historical Statistics of the United States, 1975, p. 1140, line 880; other wars: Department of the Army, History of Military Mobilization in the United States Army, 1955, appendix A.

* Yearly data were unavailable. Figures are based on war total assuming equal rate of casualties per month.

separate dummy variables for each war would remove any power from the statistical tests that are carried out below.

Because of improvements in the technology of caring for wounded and offsetting changes associated with the "efficiency" of weapons, it is possible that the casualty rate variable does not consistently measure the intensity of war at different dates. I considered using a broader casualty measure that included wounded, but the ratio of this concept to battle deaths showed no trend at least since the Spanish American War. ${ }^{23}$ Since I was unable to obtain reliable annual data on wounded for World War II, I have restricted my analysis to the narrower battle deaths concept of casualty rates.

Prospective wars would be likely also to influence current spending, with good information on forthcoming military actions existing prior to at least the U.S. entrances into World Wars I and II. Since I have been unable to construct any instruments for these war expectations, I have introduced some actual future values of $B$ into an equation for current defense spending. This procedure introduces errors-invariables problems into coefficient estimation, although the present analysis is concerned primarily with obtaining conditional forecasts rather than with coefficient estimation, per se. A later part of the

2:3 The ratio of total casualties (including wounded, but excluding deaths that were unrelated to combat) to battle deaths is $\mathbf{5 . 3}$ for the Spanish American War, 4.8 for World War I, 3.3 for World War II, 4.0 for the Korean War, and 4.3 for the Vietnamese War. See the notes to table 1 for sources of casualty data. 
empirical analysis considers a specification where future values of the $B$ variables are excluded from the estimation. Lagged effects of $B$ on spending are introduced also into the equation for defense purchases. Empirically, two annual leads, the contemporaneous value, and up to a third lag of the $B$ variable were found to be important.

Since defense expenditures involve a substantial investment component, the amount of current spending would tend to be influenced negatively by the size of existing capital stocks. Accordingly, I have included in a defense spending equation the variable $K_{t-1}^{w}$, which measures the beginning-of-period real stock of military equipment, structures, and inventories (table 2, col. $K^{w}$ ). The relation of capital stock to current spending is assumed to be given by

$$
K_{t}^{u}=b G_{t}^{w}+(1-\delta) K_{t-1}^{w},
$$

where $\delta$ is a depreciation rate and $b$ measures the fraction of total defense spending that constitutes investment (net of within-year depreciation on this investment). The $K^{w}$ series was constructed with values of $b$ and $\delta$ that varied over time (see the nn. to table 2), but I have limited the theoretical discussion below to situations where these parameters are approximated satisfactorily as constants.

The estimating equation for $G^{w}$ takes the form

$$
g_{t}^{u} \equiv\left(G^{w} / Y\right)_{t}=\alpha_{0} B_{t}+\ldots+\alpha_{3} B_{t-3}+a_{1} B_{t+1}+a_{2} B_{t+2}-\gamma k_{t-1}^{w}+u_{t},
$$

where $G_{t}^{w}$ is real defense purchases, $Y_{t}$ is real GNP, $k_{t-1}^{w} \equiv K_{t-1}^{w} / Y_{t-1}$, and $u_{t}$ is a stochastic term. Note that the dependent variable in equation (9) is $g_{t}^{w}$, the ratio of real defense purchases to real GNP. The main part of the subsequent analysis is carried out in terms of ratio variables of this type. The form of equation (9) implies that a doubling of $Y_{t}, K_{t-1}^{u}$, and $Y_{t-1}$, for given values of the $B$ variables, leads to a doubling of $G_{t}^{w}$. The model for determining $g_{t}^{w}$ over time will be used to determine the currently perceived permanent flow of real purchases when expressed relative to real GNP, $\overline{g_{t}^{w}} \equiv\left(\overline{G^{w}} / Y\right)_{t}$.

The error term in equation (9) was modeled satisfactorily as a random walk, so that estimation can be carried out readily in firstdifference form:

$D g_{t}^{\prime \prime}=\alpha_{0} D B_{t}+\ldots+\alpha_{3} D B_{t-3}+a_{1} D B_{t+1}+a_{2} D B_{t+2}-\gamma D k_{t-1}^{w}+\epsilon_{t}$,

where $D$ is the first-difference operator and $\epsilon_{t} \equiv u_{t}-u_{t-1}$ is a whitenoise error term. A constant is insignificant when added to equation (10) in the empirical analysis - that is, there is no trend in the defense purchases ratio. Moving-average error terms or more complicated autoregressive error structures also did not add to the explanatory value of the equation. 
The form of equation (10) implies that a current shock $\epsilon_{t}$-which is not associated with wartime in the sense that the values of the $D B$ variables are small-would have a permanent effect on the future mean level of $g^{w}$. Because of the inclusion of the $k_{t-1}^{w}$ term with a negative sign in equation (10), the effect on $\overline{g_{t}^{w}}$ of $\epsilon_{t}$-that is, of the current actual value $g_{t}^{w}$ with values of the $B$ variables and $k_{t-1}^{w}$ held fixed-turns out to be positive, but somewhat less than one-to-one. On the other hand, if the distribution for future values of $B$ is stationary in level form, positive values for $D B$ tend to be followed at later dates by negative values, which lead to decreases in future values of $g^{w}$. In other words wars and the accompanying levels of expenditures are modeled as temporary. This mechanism implies that an increase in $g_{t}^{w}$ that is accompanied by positive values of $D B$ will have much less effect on $\overline{g_{t}^{w}}$ than will the equivalent peacetime change in defense spending. Wartime spending has an appreciable effect on $\overline{g_{t}^{\bar{w}}}$ only to the extent that military expenditures depart from the amount associated typically with the current level of war intensity. The possibility that wars have a systematically important permanent effect on the purchases ratio is ruled out by the form of equation (10). Some alternative specifications of the error process that would have admitted this type of persisting effect were not supported empirically for the United States.

As detailed in the Appendix, equations (10) and (8) can be used to express expected future values of the defense purchases ratio, $g_{t+i}^{w}$, as a function of the latest observed ratio $g_{t}^{w}$, the value $k_{t-1}^{w}$, and actual and expected future values of the war intensity variable, $B$. Summation over these expressions with proper allowance for discounting yields a relation for the permanent purchases ratio $\overline{g_{t}^{w}}$ in terms of $g_{t}^{w}, k_{t-1}^{w}$, the array of $B$ variables, and a real discount rate $\rho$ (which equals the difference between the real interest rate and the growth rate of real GNP). Finally, a simple specification for the stochastic structure of the $B$ variable-based on the frequency, intensity, and duration of wars over the full history of the United States-is used to solve for the expected future values of the $B$ variables. With this substitution, $\overline{g_{t}^{w}}$ is determined as a function of observable magnitudes, up to the setting of a discount rate. In the case where future values of the $B$ variables are admitted into the government purchases equation (10), $\overline{g_{t}^{w}}$ ends up as a function of the values $B_{t+2}, \ldots, B_{t-3}$-that is, the values $B_{t+1}$ and $B_{t+2}$ are treated as observable at date $t$. In a situation where future values of $B$ are excluded from equation (10), $\overline{g_{t}^{w}}$ is expressed in terms of the current and lagged values, $B_{t}, \ldots, B_{t-3}$ (as well as the values of $g_{t}^{w}$ and $\left.k_{t-1}^{w}\right)$.

The main product of this exercise from the full empirical analysis is the series for temporary real defense purchases expressed relative to 
TABLE 2

Government Purchases Variables

\begin{tabular}{|c|c|c|c|c|c|}
\hline Date & $g^{w *}$ & $\overline{g^{w}} \dagger$ & $g^{w}-\overline{g^{w}}$ & $k^{w} \ddagger$ & $g^{p} \S$ \\
\hline 1889 & .0060 & $\ldots$ & $\ldots$ & $\ldots$ & .097 \\
\hline 1890 & .0057 & $\ldots$ & $\ldots$ & $\ldots$ & .094 \\
\hline 1891 & .0057 & $\ldots$ & $\ldots$ & $\ldots$ & .094 \\
\hline 1892 & .0056 & $\ldots$ & $\ldots$ & $\ldots$ & .089 \\
\hline 1893 & .0062 & $\ldots$ & $\ldots$ & $\ldots$ & .097 \\
\hline 1894 & .0064 & $\ldots$ & $\ldots$ & $\ldots$ & .102 \\
\hline 1895 & .0053 & $\ldots$ & $\ldots$ & $\ldots$ & .092 \\
\hline 1896 & .0059 & $\ldots$ & $\ldots$ & $\ldots$ & .097 \\
\hline 1897 & .0080 & $\ldots$ & $\ldots$ & $\ldots$ & .091 \\
\hline 1898 & .0192 & $\ldots$ & $\ldots$ & $\ldots$ & .094 \\
\hline 1899 & .0165 & $\ldots$ & $\ldots$ & $\ldots$ & .087 \\
\hline 1900 & .0131 & $\ldots$ & $\ldots$ & $\ldots$ & .088 \\
\hline 1901 & .0113 & $\ldots$ & $\ldots$ & $\ldots$ & .081 \\
\hline 1902 & .0110 & $\ldots$ & $\ldots$ & $\ldots$ & .084 \\
\hline 1903 & .0108 & $\ldots$ & $\ldots$ & $\ldots$ & .088 \\
\hline 1904 & .0123 & $\ldots$ & $\ldots$ & $\ldots$ & .088 \\
\hline 1905 & .0112 & $\ldots$ & $\ldots$ & $\ldots$ & .089 \\
\hline 1906 & .0093 & $\ldots$ & $\ldots$ & $\ldots$ & .082 \\
\hline 1907 & .0090 & $\ldots$ & $\ldots$ & $\ldots$ & .091 \\
\hline$! 908$ & .0117 & $\ldots$ & $\ldots$ & $\ldots$ & .110 \\
\hline 1909 & .0105 & $\ldots$ & $\ldots$ & $\ldots$ & .089 \\
\hline 1910 & .0100 & $\ldots$ & $\ldots$ & $\ldots$ & .091 \\
\hline 1911 & .0101 & $\ldots$ & $\ldots$ & $\ldots$ & .105 \\
\hline 1912 & .0094 & $\ldots$ & $\ldots$ & $\ldots$ & .100 \\
\hline 1913 & .0096 & $\ldots$ & $\ldots$ & $\ldots$ & .096 \\
\hline 1914 & .0139 & $\ldots$ & $\ldots$ & $\ldots$ & .106 \\
\hline 1915 & .0135 & $\ldots$ & $\ldots$ & $\ldots$ & .112 \\
\hline 1916 & .0164 & $\ldots$ & $\ldots$ & $\ldots$ & .093 \\
\hline 1917 & .076 & $\ldots$ & $\ldots$ & $\ldots$ & .085 \\
\hline 1918 & .258 & $\ldots$ & $\ldots$ & $\ldots$ & .080 \\
\hline 1919 & .156 & $\ldots$ & $\ldots$ & $\ldots$ & .049 \\
\hline 1920 & .038 & $\ldots$ & $\ldots$ & $\ldots$ & .085 \\
\hline 1921 & .033 & $\ldots$ & $\ldots$ & $\ldots$ & .125 \\
\hline 1922 & .017 & $\ldots$ & $\ldots$ & $\ldots$ & .116 \\
\hline 1923 & .014 & $\ldots$ & $\ldots$ & $\ldots$ & .105 \\
\hline 1924 & .014 & $\ldots$ & $\ldots$ & $\ldots$ & .116 \\
\hline 1925 & .012 & $\ldots$ & $\ldots$ & $\ldots$ & .115 \\
\hline 1926 & .011 & $\ldots$ & $\ldots$ & $\ldots$ & .108 \\
\hline 1927 & .012 & $\ldots$ & $\ldots$ & $\ldots$ & .118 \\
\hline 1928 & .013 & $\ldots$ & $\ldots$ & 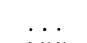 & .121 \\
\hline 1929 & .013 & $\ldots$ & $\ldots$ & .055 & .117 \\
\hline 1930 & .015 & .030 & -.015 & .056 & .141 \\
\hline 1931 & .017 & .031 & -.014 & .057 & .158 \\
\hline 1932 & .019 & .033 & -.014 & .063 & .175 \\
\hline 1933 & .016 & .032 & -.016 & .063 & .176 \\
\hline 1934 & .016 & .032 & -.016 & .056 & .187 \\
\hline 1935 & .017 & .031 & -.014 & .050 & .174 \\
\hline 1936 & .018 & .031 & -.013 & .045 & .179 \\
\hline 1937 & .016 & .029 & -.013 & .043 & .165 \\
\hline 1938 & .019 & .031 & -.012 & .046 & .187 \\
\hline 1939 & .017 & .029 & -.012 & .045 & .183 \\
\hline 1940 & .028 & .025 & .003 & .052 & .163 \\
\hline
\end{tabular}


TABLE 2 (Continued)

\begin{tabular}{|c|c|c|c|c|c|}
\hline Date & $g^{\mu * *}$ & $\overline{g^{k}} \dagger$ & $g^{\prime \prime}-\overline{g^{w}}$ & $k^{u} \ddagger$ & $g^{p} \S$ \\
\hline 1941 & .120 & .065 & .055 & .074 & .122 \\
\hline 1942 & .317 & .104 & .213 & .164 & .092 \\
\hline 1943 & .439 & .093 & .346 & .309 & .069 \\
\hline 1944 & .463 & .074 & .389 & .431 & .064 \\
\hline 1945 & .410 & .069 & .341 & .470 & .063 \\
\hline 1946 & .103 & .063 & .040 & .483 & .092 \\
\hline 1947 & .055 & .069 & -.014 & .414 & .106 \\
\hline 1948 & .056 & .072 & -.017 & .337 & .117 \\
\hline 1949 & .064 & .091 & -.026 & .290 & .132 \\
\hline 1950 & .066 & .074 & -.008 & .239 & .117 \\
\hline 1951 & .123 & .098 & .026 & .209 & .107 \\
\hline 1952 & .156 & .127 & .030 & .225 & .110 \\
\hline 1953 & .156 & .140 & .016 & .260 & .118 \\
\hline 1954 & .133 & .132 & .001 & .291 & .119 \\
\hline 1955 & .115 & .132 & -.017 & .284 & .116 \\
\hline 1956 & .112 & $: 129$ & -.017 & .283 & .115 \\
\hline 1957 & .116 & .133 & -.017 & .286 & .119 \\
\hline 1958 & .115 & .133 & -.018 & .296 & .134 \\
\hline 1959 & .108 & .129 & -.022 & .286 & .129 \\
\hline 1960 & .102 & .124 & -.022 & .282 & .133 \\
\hline 1961 & .104 & .124 & -.021 & .278 & .138 \\
\hline 1962 & .103 & .123 & -.020 & .268 & .138 \\
\hline 1963 & .096 & .116 & -.021 & .263 & .142 \\
\hline 1964 & .087 & .107 & -.021 & .251 & .145 \\
\hline 1965 & .080 & .096 & -.016 & .235 & .147 \\
\hline 1966 & .088 & .090 & -.002 & .219 & .146 \\
\hline 1967 & .098 & .086 & .011 & .216 & .149 \\
\hline 1968 & .096 & .081 & .014 & .211 & .151 \\
\hline 1969 & .088 & .080 & .009 & .206 & .150 \\
\hline 1970 & .079 & .083 & -.004 & .201 & .154 \\
\hline 1971 & .068 & .080 & -.012 & .173 & .157 \\
\hline 1972 & .063 & .076 & -.014 & .169 & .153 \\
\hline 1973 & .056 & .074 & -.017 & .153 & .148 \\
\hline 1974 & .055 & .071 & -.017 & .147 & .157 \\
\hline 1975 & .055 & .070 & -.016 & .141 & .164 \\
\hline 1976 & .050 & .067 & -.016 & .128 & .156 \\
\hline 1977 & .049 & .064 & -.015 & .118 & .152 \\
\hline 1978 & .046 & .060 & -.014 & .111 & .150 \\
\hline
\end{tabular}

* $g^{w} \equiv G^{w} / Y$, where $Y$ is real GNP (1972 base). $G^{w}$ is real defense purchases (1972 base). Data since 1929 are from National Income and Product Accounts of the United States and recent issues of the United States Survey of Current Business. The fraction of nominal defense purchases in total nominal federal purchases was multiplied by figures on real federal purchases (1972 base). Data from 1889-1928 are from Kendrick (1961, table A-1, col. 5). Figures were multiplied by 4,8 , based on the overlap for 1929 .

$+\overrightarrow{G^{2}}$ is the estimated normal defense purchases ratio, as calculated from eq. (14) in the text.

$\ddagger k^{u} \equiv K^{u} / Y$, where $K^{w}$ is the end-of-year value of net real stocks of military structures, equipment, and inventories (1972 base). Data from 1929-69 are from Kendrick (1976, table B-24) converted from a 1958 to a 1972 index by a constant multiple (1.72). Figures were extended to 1978 using data on various expenditure components: military structures, AEC structures, military equipment, AEC equipment, inventories for GSA stockpiles, and inventories for AEC stockpiles. Depreciation estimates were based on rates used by Kendrick within each category. His calculations assume a higher rate of depreciation during World War II.

$\S g^{p} \equiv G^{p} / Y$, where $G^{p}$ is real nondefense purchases of the federal plus state and local government sectors (1972 base). $G^{p}$ was calculated as total real government purchases $G$ less $G^{w}$. Sources for $G$ correspond to those above for $G^{*}$, except that Kendrick (1961, table A-IIa) was used for data from 1889-1928. 
real GNP, $\left(g^{w}-\overline{g^{w}}\right)_{t}$, which is indicated over the 1930-78 period in table 2. (This series corresponds to the choice of discount rate-the difference between the real rate of interest and the growth rate of real GNP-of .02 per year.) As is evident from the table, this variable identifies the years associated with wartime, 1940-46, 1951-53, 1966-69, as times when the defense purchases ratio is above its perceived long-run average value. Although the underlying model allows a quantitative assessment of the gap between $g_{t}^{w}$ and $\frac{g}{g_{t}^{w}}$ in the context of wars with different intensities and in an environment of nonconstant values for $\overline{g_{t}^{w}}$, it is also clear that the general pattern for the $\left(g^{u}-\overline{g^{u}}\right)_{t}$ variable would be robust to some changes in the underlying model. Notably, the important aspect of the stochastic specification for the war intensity variable $B$ is the temporary nature of wars, rather than the details of war probabilities. Substantial variations in the discount rate $\rho$ also have minor effects on the results.

It should not be surprising that the $\left(g^{w}-\overline{g^{w}}\right)_{t}$ variable exhibits a substantial amount of positive serial correlation. In this respect a gap between current and normal values-which the $\left(g^{w}-\bar{g}^{\bar{w}}\right){ }_{t}$ variable is intended to capture-should be distinguished from the spread between actual and anticipated or perceived amounts, which has been stressed in earlier analyses of monetary disturbances (Barro 1981b). The latter type of variable exhibits serial independence as a consequence of rational expectations and the assumption that information is received with, at most, a one-period lag. This type of argument does not apply to a variable that measures temporary effects. In the case of the temporary defense purchases variable, the large number of (serially correlated) peacetime years with small negative values of $\left(g^{w}-\right.$ $\left.\overline{g^{w}}\right)_{t}$ is offset by a smaller number of (serially correlated) wartime years with excesses of $g_{t}^{w}$ over $\overline{g_{t}^{w}}$. (However, the years that are significantly affected by war-for example, the set 1941-46, 1950-53, 1965-72-should not be deemed special, since they constitute 47 percent of the years since 1941 and 39 percent of those since 1946.)

\section{Government Purchases of Nondefense Items}

The nondefense portion of government purchases $-g^{p} \equiv G^{p} / Y$, where $G^{p}$ is nondefense real purchases-was examined statistically over samples beginning in 1929. This study revealed little predictive value for first differences, $D g^{p}$, except for a negative association with the contemporaneous change in the defense component, $D g^{w} .{ }^{24}$ In par-

\footnotetext{
${ }^{24}$ Past history of the residuals, lagged values of $D g^{p}$ or $D g^{w}$, a capital stock measure $D k^{p}$, and a constant were all insignificant.
} 
ticular, there is no drift in the nondefense purchases ratio. The negative association of $D g^{p}$ with $D g^{w}$ reflects the crowding out of nondefense government spending during wartime. The dependence of $D g^{p}$ only on $D g^{w}$ means that departures of $g^{p}$ from the perceived normal value $\overline{g^{p}}$ are determined completely by the difference between $g^{w}$ and $\overline{g^{w}}$. With $g^{w}-\overline{g^{w}}$ held fixed, changes in $g^{p}$ amount entirely to shifts in the permanent component of nondefense purchases. Accordingly, with the $g^{w}$ variables entered separately, the coefficient of the $g^{p}$ variable in an output equation would reveal the effects of permanent changes in nondefense purchases. It is not possible here to estimate the response of output to temporary changes in nondefense purchases, since no temporary changes were isolated over the sample.

\section{Empirical Results}

The principal empirical analysis involves joint estimation of the government purchases equation (10) and a relation for output that is based on the form of equation (4). With the defense and nondefense components of government purchases entered separately, the output equation becomes

$$
\log \left(Y_{t}\right)=\ldots+\beta_{1}\left(g^{w}-\overline{g^{w}}\right)_{t}+\beta_{2} \overline{g_{t}^{w}}+\beta_{3} g_{t}^{p} .
$$

Note that the real government purchases variables all appear as ratios to real GNP. The variable $\overline{g_{t}^{w}} \equiv\left(\overline{G^{w}} / Y\right)_{t}$ is determined as a function of observables from equation (10) when used in conjunction with some relations that are derived in the Appendix (eqq. [A5] and [A6]).

The first set of hypothesis tests involves the output effects of the $\left(g^{w}-\overline{g^{w}}\right)_{t}$ and $\overline{g_{t}^{w}}$ variables in equation (11)-specifically, that the coefficients of these variables satisfy the restrictions, $0 \leqslant \beta_{2} \leqslant \beta_{1} \leqslant 1$. As indicated earlier, the coefficient on the $g_{t}^{p}$ variable, $\beta_{3}$, reveals the output effect of a permanent change in nondefense purchases. If nondefense purchases were characterized by closer substitutability with private consumption expenditure (the $\theta$ parameter) and by lesser impact on private production (the MPG parameter) than defense purchases, then $\beta_{2}>\beta_{3}$ would follow. However, this condition cannot be viewed as a firm implication of the theory. The model also suggests the restriction, $0 \leqslant \beta_{3} \leqslant 1$.

The second set of hypothesis tests checks whether the explanatory variables for $\overline{g_{t}^{u}}$-in this case $B_{t+2}, \ldots, B_{t-3}$ and $k_{t-1}^{u}$-enter an unrestricted reduced form for output as determined solely by their role in determining $\overline{g_{t}^{w}}$ in accordance with the coefficients of equation (10).

The analysis is contingent on a value of the discount rate $\rho$-the difference between the real interest rate and the growth rate of real 
GNP - in the calculation of the $\overline{g_{t}^{w}}$ variable (see eqq. [A5] and [A6] in the Appendix). However, the results turn out to be relatively insensitive to variations in the $\rho$ parameter at least over the range from .01 to .05 per year. The reported results refer to a fixed value of $\rho=.02$ per year, which is a plausible magnitude, ex ante, and which approximates the maximum likelihood estimate for this parameter.

Jointly estimated equations for real defense purchases and real GNP were calculated by means of a nonlinear, maximum likelihood routine from the TSP regression package, which includes estimation of contemporaneous covariances for the error terms. The estimation is joint in the sense of incorporating the role of the coefficients from equation (10) in determining the series $\overline{g_{t}^{w}}$ and thereby influencing the fit for output in the form of equation (11). In particular, the coefficients in the equation for $D g_{t}^{w}$ are not determined solely to obtain a best fit of equation (10). I have not carried out joint estimation in the broader context of choosing the number of leads and lags of the $B$ variable to include equation (10), in deciding to omit moving-average error terms in this equation, in analyzing the process for nondefense purchases, and so on.

Since the dependent variable, real GNP, appears also in the denominators of the ratio variables $g^{w}$ and $g^{p}$, there is a possible simultaneity problem in the estimation. Accordingly, I have used as instruments for $g_{t}^{w}$ and $g_{t}^{p}$ the lagged values, $g_{t-1}^{w}$ and $g_{t-1}^{p}$, and also the contemporaneous values, $G_{t}^{w} / \bar{Y}_{t}$ and $G_{t}^{p} / \bar{Y}_{t}$, where $\bar{Y}_{t}$ is the trend value of real GNP, as determined from a regression over the 1946-78 period of $\log (\mathrm{GNP})$ on a constant and time. The estimates are not altered substantially if only the pair of lagged values or only the pair of contemporaneous values relative to trend are used as instruments. Empirically, the movements in $g_{t}^{w}$ are dominated sufficiently by conditions of war or peace that the use of instruments yields estimates for the coefficients of the $\left(g^{w}-\overline{g^{w}}\right)_{t}$ and $\overline{g_{t}^{w}}$ variables in equation (11) that differ only in minor ways from ordinary-least-squares (OLS) values. However, the use of instruments is important in the case of the $g_{t}^{p}$ variable-OLS estimates for the $\beta_{3}$ coefficient in equation (11) appear to be biased downward substantially because of the inclusion of $Y_{t}$ in the denominator of the $g_{t}^{p}$ variable.

\section{Results for Post-World War II Output Sample}

For an output sample that begins in 1946, the results of the joint estimation of equations (10) and (11) are, for the 1932-78 sample:

$$
D g_{t}^{w}=\underset{(.013)}{.163 D B_{t+2}+.198 D B_{t+1}+.273 D B_{t}+.240 D B_{t-1}}
$$




$$
\begin{gathered}
-.022 D B_{t-2}+.088 D B_{t-3}-.26 D k_{t-1}^{u}, \\
(.015) \quad(.016) \quad(.08) \\
\hat{\sigma}=.0143, \mathrm{D}-\mathrm{W}=1.7 ;
\end{gathered}
$$

and for the 1946-78 sample:

$$
\begin{aligned}
& \log \left(Y_{t}\right)=2.97+.0343 \cdot t+.83 D M R_{t}+1.12 D M R_{t-1} \\
& \text { (.04) (.0008) (.22) } \\
& +.99\left(g^{w}-\overline{g^{w}}\right)_{t}+.55 \overline{g_{t}^{u}}+.62 g_{t}^{p}, \\
& \text { (.21) (.12) (.45) } \\
& \hat{\sigma}=.0143, \mathrm{D}-\mathrm{W}=1.5 \text {. }
\end{aligned}
$$

Asymptotic standard errors are shown in parentheses below the coefficient estimates. The $\hat{\sigma}$ values are asymptotic estimates of the standard errors of the disturbance terms; D-W is the Durbin-Watson statistic. Note that the sample for the government purchases equation (12) begins in 1932 and thereby includes the World War II experience.

Variables included in equations (12) and (13) are: $Y$, real GNP (1972 base); $t$, time trend; $D M R \equiv D M-\hat{D M}$ is "unanticipated money growth," as measured in earlier research (Barro $1981 b$ ), where $\hat{D M}$ is an estimated value of money growth from an equation that is based on the $M 1$ definition of the money stock; ${ }^{25} g^{w} \equiv G^{w / Y}$, where $G^{w}$ is real defense purchases (1972 base); $g^{p} \equiv G^{p} / Y$, where $G^{p}$ is real, nondefense, federal plus state and local purchases (1972 base); $B$, casualty rate variable as defined in table 1 ; and $k^{w} \equiv K^{w / Y}$, where $K^{w}$ is real government defense capital stocks (1972 base).

For present purposes I focus on the role of the government purchases variables in equation (13). The money shock variables have effects that are similar to those discussed in previous research, as reported in Barro (1981b).

The $\overline{g_{t}^{w}}$ variable in the output equation is based on the specification for $D g_{t}^{w}$ that appears in equation (12). The main result from this equation is the strong positive spending effect of wars, as measured by the casualty rate variable $B$. The equation shows a 2 -year lead effect of the $B$ variable and a lagged effect out to 3 years. (The negative effect on $D g_{t}^{w}$ of the $D B_{t-2}$ variable is difficult to interpret.) The consequences of eliminating the future values of $D B$ from this equation are

${ }^{25} \hat{D M}$ is determined from an equation that is estimated over the 1941-78 sample:

$$
\hat{D M_{t}}=\underset{(.024)}{.095}+.49 D M_{t-1}+.16 D M_{t-2}+\underset{(.14)}{.069 \mathrm{FEDV}_{t}}+.030 \cdot \log [U /(1-U)]_{t-1},
$$

where observations from 1941-45 are weighted by $.36 . \mathrm{FEDV}_{t}$ is real federal spending relative to a distributed lag of itself, and $U$ is the unemployment rate in the total labor force. See Barro $(1981 b)$ for a discussion of this type of equation. 
discussed later. For present purposes the most important aspect of war spending is its temporary nature, although precise calculations for $\overline{g_{t}^{w}}$ involve the distributed lag pattern of $D B$ effects on $D g_{t}^{w}$ and the implications of these responses for the behavior of the capital stock ratio $k^{w}$. Equation (12) shows also the expected negative effect of $D k_{t-1}^{w}$ on $D g_{t}^{w}$.

Using equations (A5), (A6), and (A11) from the Appendix, and the value $\rho=.02$ for the discount rate, the point estimates of coefficients that appear in equation (12) can be shown to imply the formula for $\overline{g_{t}^{u}}$ as follows:

$$
\begin{aligned}
\overline{g_{t}^{u t}}= & .011+.67 g_{t}^{u}+.15 k_{t-1}^{u}-.06 B_{t-3}+.02 B_{t-2}-.16 B_{t-1} \\
& -.18 B_{t}-.12 B_{t+1}-.07 B_{t+2} .
\end{aligned}
$$

This relation is a particular form of equation (6). Equation (14) shows a positive but less than one-to-one effect on $\overline{g_{t}^{u}}$ of $g_{t}^{u}$, a positive effect of $k_{t-1}^{u \prime}$ (for a given value of $g_{t}^{u}$ ), and a basically negative effect of the casualty rate variables (again given the value of $g_{t}^{w}$ ). Values of $\overline{g_{t}^{u}}$ that are calculated from equation (14) are shown along with values of $g_{t}^{u}$ in table 2.

The temporary defense purchases variable, $\left(g^{u}-\overline{g^{u}}\right)_{t}$, has a significantly expansionary effect on output. The estimated coefficient ${ }^{26}$ in equation (13) is $\hat{\beta}_{1}=.99$, S.E. $=.21$. The " $t$-value" corresponding to $\beta_{1}=0$ is 4.7 . The normal defense purchases variable, $\frac{g_{t}^{\prime \prime}}{}$, is also significantly expansionary in this equation $-\hat{\beta}_{2}=.55$, S.E. $=.12$, which implies a $t$-value of 4.6. The estimated effect for the permanent purchases variable is somewhat greater than half that of the estimated temporary effect. ${ }^{27}$ The results permit rejection of two extreme hypotheses: first, that only the temporary part of purchases affects output (which would require $\hat{\beta}_{2}$, the estimated coefficient of the $\overline{g_{t}^{w}}$ variable in eq. [13], to differ insignificantly from zero),

${ }^{26}$ Because of the negative correlation of $\left(g^{w}-\overline{g^{u}}\right) t$ with $g_{t}^{p}$, the $\beta_{1}$ coefficient picks up an additional effect. The extra term involves the difference between the output effects of permanent and temporary nondefense purchases. The output coefficient associated with temporary nondefense purchases could not be estimated with the available data. However, since the regression coefficient of $g_{t}^{p}$ on $\left(g^{u}-\overline{g^{w}}\right)_{t}$ is on the order of -0.1 , it is unlikely that the overall modification is important.

${ }^{27}$ It has been suggested that the temporary government purchases variable may be proxying for the effects of accompanying federal deficits. The analysis in Barro (1979) documents the strong positive effect of temporary federal spending, as in wartime, on public-debt issue. Some preliminary results in Barro (1980b) indicate that lagged "debt shocks" have expansionary effects on output that are statistically significant but substantially weaker than those of monetary shocks. However, this constructed debt-shock variable filters out the normal positive association between temporary government spending and the deficit. With these debt shocks held fixed, the actual lagged values of public-debt growth have no explanatory value for output. This last finding suggests that the strong expansionary influence of temporary defense purchases does not involve a proxying for the effect of correlated movements in the federal deficit. 
and second, that temporary and permanent purchases are of equal importance for output. The latter case would correspond to equal coefficients $\left(\beta_{1}=\beta_{2}\right)$ for the $\left(g^{u}-\overline{g^{u}}\right)_{t}$ and $\overline{g_{t}^{u}}$ variables - that is, to the proposition that the coefficient of the $\overline{g_{t}^{\prime \prime}}$ variable would be zero in an equation that held fixed the value of the actual purchases ratio, $g_{t}^{u}$. For convenience, the results from equation (13) can be rewritten in this form as

$$
\log \left(Y_{t}\right)=\ldots+.99 g_{t}^{u}-.44 \overline{g_{t}^{u}} .
$$

The hypothesis that the coefficient of the $\overline{g_{t}^{u}}$ variable equals zero corresponds to a $t$-value of 1.8 , which is significant at the 5 percent level for the case of this one-sided test. That is, the null hypothesis of equal output effects for temporary and permanent defense purchases $\left(\beta_{1}=\beta_{2}\right.$ in eq. [11]) is rejected in favor of the hypothesis that temporary purchases are more expansionary, $\beta_{1}>\beta_{2} \cdot{ }^{28}$

The estimated coefficient on the $\left(g^{u}-\overline{g^{u}}\right)_{t}$ variable in equation (13) implies that a temporary change in the level of real defense purchases has almost a one-to-one effect on the contemporaneous level of output. While this finding is consistent with the restriction, $\beta_{1} \leqslant 1$, the evidence would also be consistent with a moderate multiplier relationship between temporary government purchases and output. The relatively high estimated output effect is associated in the theoretical model with a small value of the $\theta$-coefficient, a high value of the MPG parameter, and a high real-rate-of-return elasticity of aggregate supply relative to that of demand.

The estimated coefficient on the $\overline{g_{t}^{\bar{w}}}$ variable in equation (13) implies that a permanent increase by one unit in real defense purchases leads approximately to a one-half unit rise in real GNP. This result accords with the restriction $\beta_{2} \leqslant 1$-moreover, the estimate is significantly below unity in this case.

The estimated coefficient of $g_{t}^{p}$, the nondefense purchases ratio, is

${ }^{28}$ I considered discriminating between temporary and permanent defense purchases by utilizing a measure of the return on the equities of defense contractors relative to that on a market portfolio of New York Stock Exchange (NYSE) stocks. (The relativereturns variable was constructed using data on total returns to NYSE stocks from the Center for Research in Security Prices of the University of Chicago. A list of defense contractors and the size of these contracts for 1969 from the Department of Defense was kindly supplied to me by Claire Friedland.) This relative-returns variable has no explanatory power when added to a first-difference form of the output equation with $D g_{t}^{u}, D g_{t}^{p}$, and the determinants of $\overline{D g_{t}^{w}}$ from the form of eq. (12) included as independent variables. Conceptually, it is unclear whether the relative-returns variable signifies an increase in war probability and, therefore, that current defense expenditures are more likely to be temporary, or an increase in the long-run expected quantity of defense purchases, which would imply that current defense expenditures are more likely to be permanent. Therefore, the sign of the variable is ambiguous on theoretical grounds. 
$\hat{\beta}_{3}=.62$, S.E. $=.45$, which is positive but imprecisely determined. The relatively small amount of independent sampling variation in this variable since 1946, in conjunction with the necessity of using instrumental variables, results in the high standard error. (Using OLS techniques, the estimated coefficient of the $g_{t}^{p}$ variable is negative.) In any event the hypothesis that the coefficients of the $g_{t}^{p}$ and $g_{t}^{\bar{u}}$ variables are equal, $\beta_{2}=\beta_{3}$, would be accepted from the present evidence. As noted earlier, the relative output effects for these two types of permanent movements in government purchases depend, in the theoretical model, on the relative values of the $\theta$ and MPG parameters. Possibly, a more precise determination of the $g_{t}^{p}$ coefficient would be obtained by extending the analysis to the 1930s, during which major changes occurred in the nondefense purchases ratio. The main obstacle for this extension is the isolation of monetary shocks, which seems to require a specification for the pre-World War II monetary regime that differs from that used for the post-1941 period (see n. 25 above). ${ }^{29}$

A combination of equation (11) with an expression for $\overline{g_{t}^{u}}$ in the form of equation (14) implies a reduced-form relation for output in terms of a constant, a time trend, $D M R$ variables, $g_{t}^{u \prime}, g_{t}^{p}$, the $B$ variables, and $k_{t-1}^{\prime \prime}$. Unrestricted estimation of this reduced form affords a test of the hypothesis that the determinants of $\overline{g_{t}^{u}}$-specifically, the $B$ variables and $k_{t-1}^{\prime \prime}$-affect output only in the manner implied by the forms of equations (11) and (14). The test is based on the likelihood ratio corresponding to unrestricted and restricted forms of joint estimation. The value of $-2 \cdot \log$ (likelihood ratio) turns out to be 3.2 , which is below the 5 percent critical value for the $\chi^{2}$ distribution with 6 degrees of freedom (the number of coefficient restrictions in this case) of $12.6 .^{30}$ Therefore, the hypothesis that the determinants of $\overline{g_{t}^{u}}$ enter only in this indirect manner in influencing output is accepted.

2:9 It is worth noting that the point estimates for the government purchases coefficients in eq. (13) change little if the output equation is respecified in firstdifference form (see Plosser and Schwert [1978] for a discussion). The estimated equation in this case is, for the 1946-78 sample:

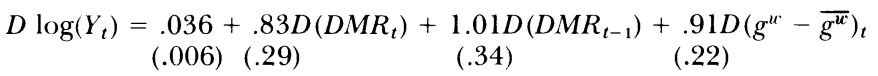

$$
\begin{aligned}
& +.55 D \overline{g_{t}^{\prime \prime}}+0.63 D g_{t}^{p}, \quad \hat{\sigma}=.0176, \mathrm{D}-\mathrm{W}=2.5 \text {. } \\
& \text { (.39) (1.67) }
\end{aligned}
$$

The jointly estimated equation for $D g_{t}^{w}$ is similar to that shown in eq. (12). Note that the constant in the equation for $D \log \left(Y_{t}\right)$ corresponds to the time trend for the level equation. The main change from the previous specification is the higher standard errors for the $\overline{g_{t}^{u}}$ and $g_{t}^{p}$ coefficients. The Durbin-Watson statistic of 2.5 suggests overdifferencing.

${ }^{30}$ If the discount rate $\rho$ were regarded as a freely estimated parameter, there would be only 5 degfees of freedom, which would imply a critical value of 11.1 . 
There would, of course, be many possible output effects of war that do not operate through the channels that were specified in the present model. For example, there would be responses to conscription and patriotism, and the possibility that war would threaten future property rights. Some of these effects would, however, influence output in a manner similar to that of the pecuniary intertemporal substitution variable that was stressed in the theoretical analysis (see Barro [1981 $a$ ] for a discussion of wartime influences on financial rates of return). In particular, the level of temporarily high demands on resources by the government, $\left(g^{u v}-\overline{g^{u t}}\right)_{t}$, may proxy satisfactorily for the full range of wartime output effects.

More generally, because the war variables are the prime basis in this work for distinguishing temporary from permanent movements in government purchases, it would be infeasible to allow unrestricted direct wartime output effects and still carry out interesting tests of the underlying hypotheses. In any event the restriction that the war variables influence output only indirectly through influences on temporary government purchases is satisfied in the present case.

Elimination of future values of the casualty rate variable from the government purchases equation (12) has a substantial effect on the estimation of this equation for the 1932-78 sample. Aside from a major deterioration in fit, the residuals then show pronounced positive serial correlation. These effects are dominated by the World War II years - in particular, from the rise in military spending in 1940-41 prior to the onset of casualties and from the major advance in spending in 1942-43 before the peak in casualties for 1944-45. In these cases it seems reasonable to treat the future casualty values as rough proxies for contemporaneously available information about the intensity of the war. (Another possibility would be to use a foreign casualty rate variable, but data limitations and conceptual problems concerning the perceived threat attached to foreign conflicts have prevented the implementation of this idea.)

For the post-World War II period, this type of advance information on war intensity seems less important and, in fact, the future casualty variables lack significant explanatory power for defense expenditures over this period. With these future values deleted and 1946-78 samples used throughout, the results of the joint estimation are, for the 1946-78 sample:

$$
\begin{aligned}
D g_{t}^{u t}= & .264 D B_{t}+.226 D B_{t-1}-.027 D B_{t-2}+.079 D B_{t-3} \\
(.061) \quad(.043) & (.021) \\
-.30 D k_{t-1}^{u}, & \hat{\sigma}=.0128, \mathrm{D}-\mathrm{W}=1.9 ; \\
& \quad(.11)
\end{aligned}
$$


and

$$
\begin{aligned}
& \log \left(Y_{t}\right)=2.99+.0340 \cdot t+.88 D M R_{t}+1.12 D M R_{t-1} \\
& \text { (.06) }(.0010) \quad(.25) \\
& +.96\left(g^{u}-\overline{g^{u}}\right)_{t}+.52 \overline{g_{t}^{u}}+.74 g_{t}^{p} \text {, } \\
& \text { (.26) (.17) (.52) } \\
& \hat{\sigma}=.0177, \mathrm{D}-\mathrm{W}=1.5 \text {. }
\end{aligned}
$$

Although the fit of the estimated output equation (16) is poorer than that shown in equation (13), the pattern of estimated coefficients and standard errors is similar. Therefore, the conclusions on output effects of the government purchases variables are not sensitive to, first, elimination of the World War II years from the sample for the government purchases equation and, second, removal of the future values of the casualty rate variable from this equation. The results also remain similar if the starting date for the output equation is shifted from 1946 to 1950, which removes some contribution of the World War II years that works through the effects of lagged $B$ values on the constructed $\overline{g_{t}^{\prime \prime}}$ variable.

\section{Addition of World War II Output Experience}

Rather than insulating the results from World War II, it is in many respects more informative to evaluate the performance of the model during this extreme experience. Clearly, the sample variation in the wartime-related variable, $\left(g^{w}-\overline{g^{w}}\right)_{t}$, is raised enormously by this extension of coverage. On the other side, the inclusion of the World War II years raises problems that concern the measurement of real output during a period of extensive price controls and the accuracy of linear specifications for extreme observations.

Jointly estimated equations that include the 1942-45 observations on output are, for the 1932-78 sample:

$$
\begin{aligned}
& D g_{t}^{\prime \prime}=.163 D B_{t+2}+.196 D B_{t+1}+.274 D B_{t}+.242 D B_{t-1} \\
& \begin{array}{llll}
(.013) & (.013) & (.015) & (.017)
\end{array} \\
& -.022 D B_{t-2}+.087 D B_{t-3}-.25 D k_{t-1}^{u r} \text {, } \\
& \begin{array}{lll}
(.015) \quad(.016) \quad(.08) & 0
\end{array} \\
& \hat{\sigma}=.0143, \mathrm{D}-\mathrm{W}=1.7
\end{aligned}
$$

and for the 1942-78 sample:

$$
\begin{aligned}
\log \left(Y_{t}\right)= & 2.97+.0350 \cdot t+.76 D M R_{t}+.90 D M R_{t-1} \\
& (.05)(.0009)
\end{aligned}
$$




$$
\begin{gathered}
+.71\left(g^{\prime \prime}-\overline{g^{u t}}\right)_{t}+.42 \overline{g_{t}}+.14 g_{t}^{p}, \\
(.06) \quad(.12) \quad(.51) \\
\hat{\sigma}=.0154, \mathrm{D}-\mathrm{W}=1.4 .
\end{gathered}
$$

A test that the 1942-45 observations for output conform to the same structure as that for the other years corresponds to a value for $-2 \cdot \log$ (likelihood ratio) of 37.9 , which exceeds the 5 percent critical value of the $\chi^{2}$ distribution with 4 degrees of freedom of $9.5 .{ }^{31}$ It seems likely that this appearance of structural break during World War II would not appear if the functional form were altered to allow for a nonlinear dependence of $\log \left(Y_{t}\right)$ on $\left(g^{u t}-\overline{g^{t t}}\right)_{t}$. Specifically, the most important change from the 1946-78 estimates in equation (13) to the $1942-78$ values in equation (18) seems to be the drop in the estimated coefficient of the $\left(g^{w}-\bar{g}^{w}\right)_{t}$ variable, $\hat{\beta}_{1}$, from .99 , S.E. $=$ .21 , to .71, S.E. $=.06$. A functional representation that allowed for positive, but diminishing, output effects of temporary government purchases would probably account for the overall results in a homogeneous form, but I have not experimented along these lines. As the results in equation (18) stand, they reveal the anticipated reduction in the standard error of the $\left(g^{u t}-\overline{g^{u t}}\right)_{t}$ coefficient - in fact, if this relation were viewed as well specified, the estimated output effect of temporary government purchases, $\hat{\beta}_{1}$, would now be measured as significantly less than one. ${ }^{32}$

${ }^{31}$ I have also carried out the estimation with an allowance for heteroscedasticity in the form of a different error variance for the output equation during the World War II years, 1942-45. Maximum likelihood estimates indicate that those years have an error variance that is 2.6 times that for the 1946-78 period, which corresponds to multiplying the 1942-45 observations by .62 in the estimation. The results with the heteroscedasticity correction applied are, for the 1942-78 sample:

$$
\begin{aligned}
\log \left(Y_{t}\right)= & 2.98+.0347 \cdot t+.85 D M R_{t}+ \\
& (.04)(.0009) \quad(.17) \quad(.17) \\
& +.75\left(g^{\prime \prime}-\overline{g^{t \prime}}\right)_{t}+.48 \overline{g_{t}^{u}}+.34 g_{t-1}^{p}, \hat{\sigma}=.0148, \mathrm{D}-\mathrm{W}=1.4 . \\
& (.07) \quad(.12) \quad(.53)
\end{aligned}
$$

Note that the $\hat{\sigma}$ value applies here to the error term for the 1946-78 period. The pattern of results does not differ greatly from that shown in eq. (18). The jointly estimated government purchases equation is very close to that shown in eq. (17). A test for the addition of the 1942-45 years for output to the rest of the sample corresponds here to a value for $-2 \cdot \log$ (likelihood ratio) of 30.9 , as compared to a 5 percent $\chi^{2}$ value with 3 degrees of freedom of 7.8. (The degrees of freedom are reduced by 1 here in comparison with the test for the context of homoscedasticity because of the estimation of the heteroscedasticity parameter.)

${ }^{32}$ The estimated coefficient for nondefense purchases, $g_{t}^{p}$, is also smaller than before, but still insignificantly different from that on the $\overline{g_{t}^{u \prime}}$ variable. With $g_{t}^{u \prime}$ held fixed, the implied estimated coefficient on $\overline{g_{t}^{\prime \prime}}$ is now $-.29, \mathrm{~S} . \mathrm{E} .=.12$. That is, the hypothesis that temporary and permanent defense purchases have equal output effects- $\beta_{1}=\beta_{2}$ corresponds here to a $t$-value of 2.4. This hypothesis would, therefore, again be rejected in favor of $\beta_{1}>\beta_{2}$. A test that the determinants of $\overline{g_{t}^{u}}$ from eq. (17) enter only in this 


\section{Conclusions}

The empirical part of this study documents the positive output effect of defense purchases. There is evidence that temporary movements in defense purchases, which are associated primarily with wartime, produce roughly double the response in output as that generated by equal-sized, but permanent, shifts in defense purchases. In all cases the results are consistent with a dampened, rather than a multiplicative, response of output. The effects of nondefense purchases are imprecisely determined.

The theoretical section stresses intertemporal substitution variables as the channel for the strong positive output effect of temporary shifts in government purchases. Preliminary empirical analysis of realized real rates of return (Barro 1981a) provides some support for this mechanism, but further joint consideration of output and real-rateof-return behavior would constitute useful research.

\section{Appendix}

\section{Derivation of the Permanent Defense Purchases Ratio, $\overline{g^{w}}$}

Equation (10) can be written in the form,

$$
D g_{t}^{\prime \prime}=A(L) D B_{t}-\gamma D k_{t-1}^{\prime \prime}+\epsilon_{t},
$$

where $A(L)$ is a polynomial in the lag operator $L$, which allows both lags and leads of $D B_{t}$ to affect $D g_{t}^{\prime \prime}$. Using equation (8), the evolution of $k^{\prime \prime}$ is governed by

$$
k_{t}^{\prime \prime}=b g_{t}^{\prime \prime}+\left(1-\delta^{\prime}\right) k_{t-1}^{\prime \prime \prime},
$$

where $\left(1-\delta^{\prime}\right) \equiv(1-\delta)(1-\lambda)$ and $\lambda$ is the (assumed constant) growth rate of real GNP.

Equations (A1) and (A2), together with a specification for the stochastic structure of the $B$ variable, imply a distribution for future values of $g^{u \text {, }}$ conditional on information available at date $t$ (which is assumed in the present case to include the values of $B_{t+1}$ and $B_{t+2}$ ). Equation (A1) implies that future values of the spending-GNP ratio are given by

$$
g_{t+i}^{u}=g_{t}^{\prime \prime}+A(L)\left(B_{t+i}-B_{t}\right)-\gamma\left(k_{t+i-1}^{u \prime}-k_{t-1}^{u}\right)+\text { error term. }
$$

Equation (A2) can be used repeatedly to eliminate future values of $k^{\prime \prime}$ from equation (A3), which leads eventually to the condition.

indirect manner in influencing output leads to a value for $-2 \cdot \log (\operatorname{likelihood}$ ratio) of 17.4 , as compared to a 5 percent critical value for the $\chi^{2}$ distribution with 6 degrees of freedom of 12.6. With a heteroscedasticity correction applied for 1942-45 (see n. 31 above), the corresponding statistic is 10.3 . Therefore, with the World War II observations included in the output sample, there is greater indication of an output effect of war that operates directly and not only through the $\left(g^{u}-\overline{g^{u}}\right)_{t}$ variable. However, this conclusion could also be affected by inappropriate linear specification of eq. (18). 


$$
\begin{aligned}
g_{t+i}^{\prime \prime \prime}= & g_{t}^{\prime \prime}\left[\frac{\delta^{\prime}+b \gamma\left(1-\delta^{\prime}-b \gamma\right)^{i}}{\delta^{\prime}+b \gamma}\right] \\
& +b \gamma k_{t-1}^{\prime \prime}\left[\frac{1-\left(1-\delta^{\prime}-b \gamma\right)^{i}}{\delta^{\prime}+b \gamma}\right]+A(L)\left(B_{t+i}-B_{t}\right) \\
& -b \gamma\left[A(L) B_{t+i}+\left(1-\delta^{\prime}-b \gamma\right) A(L) B_{t+i-2}\right. \\
& \left.+\ldots+\left(1-\delta^{\prime}-b \gamma\right)^{i-2} A(L) B_{t+1}\right]+ \text { error term. }
\end{aligned}
$$

The bracketed expression multiplying $g_{t}^{\prime \prime}$ is positive but less than one, as indicated in the text. The coefficient on $k_{t-1}^{\prime \prime}$ is positive-that is, future values of $g_{t+i}^{\prime \prime}$ rise with $k_{t-1}^{\prime \prime}$ for a given value of $g_{t}^{\prime \prime}$ - because $k_{t-1}^{\prime \prime}$ exerted a depressing effect on $g_{t}^{\prime \prime}$ that should be filtered out in determining the "permanent component" of $g_{t}^{\prime \prime}$. The term $A(L)\left(B_{t+i}-B_{t}\right)$ measures the temporary effect of the $B$ variable on $g_{t+i}^{\prime \prime}$ relative to that on $g_{t}^{\prime \prime}$ (which is filtered out as above in obtaining the permanent component of $\left.g_{t}^{\prime \prime}\right)$. The final bracketed term accounts for the interaction between $B$-induced temporary spending and the resulting negative effect of the implied accumulation of $k^{\prime \prime}$ on subsequent spending.

The variable of interest for output determination is

$$
\overline{g_{t}^{u}}=\left(\frac{\rho}{1+\rho}\right)\left[g_{t}^{\prime \prime}+\sum_{i=1}^{\infty} E g_{t+i}^{u \prime} /(1+\rho)^{i}\right],
$$

where $E$ is the expectation operator. The discount rate is $\rho=r-\lambda$, where $\lambda$ is again the growth rate of real GNP. The variable $\overline{g_{t}^{u}}$ can be determined from summation over $i$ in equation (A4) to be

$$
\begin{aligned}
\overline{g_{t}^{\prime \prime}}= & g_{t}^{\prime \prime}\left(\frac{\rho+\delta^{\prime}}{\rho+\delta^{\prime}+b \gamma}\right)+k_{t-1}^{\prime \prime}\left(\frac{\delta^{\prime} \lambda}{\rho+\delta^{\prime}+b \gamma}\right) \\
& +\Phi_{t}\left(\frac{\rho}{1+\rho}\right)\left(\frac{\rho+\delta^{\prime}}{\rho+\delta^{\prime}+b \gamma}\right),
\end{aligned}
$$

where $\Phi_{t} \equiv \sum_{i=1}^{x} E\left[A(L)\left(B_{t+i}-B_{t}\right)\right] /(1+\rho)^{i}$. Again, the effect of $g_{t}^{\prime \prime}$ is positive but less than unitary, and the effect of $k_{t-1}^{\prime \prime}$ is also positive.

For the case where $A(L)=\alpha_{0}+\alpha_{1} L+\alpha_{2} L^{2}+\alpha_{3} L^{3}+a_{1}(1 / L)+a_{2}(1 / L)^{2}$, and where observations on the $B$ variable through $B_{t+2}$ are available at date $t$, the $\Phi_{t}$ expression in the last term of equation (A5) can be written as

$$
\begin{aligned}
\Phi_{t}= & B_{t-3}\left(-\alpha_{3} / \rho\right)+B_{t-2}\left[-\alpha_{2} / \rho+\alpha_{3} /(1+\rho)\right]+B_{t-1}\left[-\alpha_{1} / \rho+\alpha_{2} /(1+\rho)\right. \\
& \left.+\alpha_{3} /(1+\rho)^{2}\right]+B_{t}\left[-\alpha_{0} / \rho+\alpha_{1} /(1+\rho)+\alpha_{2} /(1+\rho)^{2}+\alpha_{33} /(1+\rho)^{3}\right] \\
& +B_{t+1}\left[-a_{1} / \rho+\alpha_{0} /(1+\rho)+\alpha_{1} /(1+\rho)^{2}+\alpha_{2} /(1+\rho)^{3}+\alpha_{3} /(1+\rho)^{4}\right] \\
& +B_{t+2}\left[-a_{2} / \rho+a_{1} /(1+\rho)+\alpha_{0} /(1+\rho)^{2}+\alpha_{1} /(1+\rho)^{3}+\alpha_{2} /(1+\rho)^{4}\right. \\
& \left.+\alpha_{33} /(1+\rho)^{5}\right]+\Psi_{t}\left[a_{2}+a_{1} /(1+\rho)+\alpha_{0} /(1+\rho)^{2}\right. \\
& \left.+\alpha_{1} /(1+\rho)^{3}+\alpha_{2} /(1+\rho)^{4}+\alpha_{3} /(1+\rho)^{5}\right],
\end{aligned}
$$

where $\Psi_{t} \equiv \sum_{i=1}^{x} E B_{t+i+2} /(1+\rho)^{i}$ is a variable that measures the effect on expected future spending of anticipated future wars (in the present case from year $t+3$ onward).

The variable $\overline{g_{t}^{\prime \prime}}$ in equation (A5) is now related to various parameters and the variables $g_{t}^{\prime \prime}, k_{t-1}^{\prime \prime}, B_{t-3}, \ldots, B_{t+2}$, and $\Psi_{t}$. The remaining work is to relate expectations of future values of $B$, as entering through the $\Psi_{t}$ variable, to currently observed variables, including values of $B$ up to $B_{t+2}$. 


\section{Expectations of Future Wars}

Calculation of expected future casualty rates is based on the following stationary probability model for wars. ${ }^{33}$ First, a $2 \times 2$ matrix is specified for the probability of war or peace next year (or rather for year $t+3$ when conditions at $t+2$ are assumed known at date $t$ ), conditional on war or peace prevailing currently. It is assumed that information about the future course of $B$ is contained fully in the most recent observation, earlier values of $B$ and values of other variables not having to be considered. The probability of war during at least part of next year, given peace for the latest observation, is based on data over the 1774-1978 period-namely,

$$
p_{1}=\operatorname{Prob}\left(B_{t+1}>0 \mid B_{t}=0\right)=9 / 162=.06,
$$

where 162 is the total number of peacetime years in the sample (where $B_{t}=$ 0 ), and 9 is the number of these years that were followed by the outbreak of war. ${ }^{34}$ Correspondingly, the probability of peace continuing is given by

$$
\left(1-p_{1}\right)=\operatorname{Prob}\left(B_{t+1}=0 \mid B_{t}=0\right)=.94 \text {. }
$$

The value of $p_{1}$ is slightly higher if the sample is limited to the more recent period 1889-1978 (the sample for which relatively accurate observations on $G^{\prime \prime}$ and $B$ are available), for which the result is $p_{1}=5 / 68=.07$.

The probability of the continuation of war is given for the 1774-1978 sample by

$$
p_{2}=\operatorname{Prob}\left(B_{t+1}>0 \mid B_{t}>0\right)=33 / 42=.79,
$$

where 42 is the number of war years (where $B_{t} \neq 0$ ), and 33 is the number of these that were followed by another year of war. ${ }^{35}$ In other words nine wars began and ended over the sample 1774-1978. For the 1889-1978 period, the result would be $p_{2}=16 / 21=.76$. Finally, the probability of no war next year, given its existence this year, ${ }^{36}$ is given for the $1774-1978$ sample by

$$
\left(1-p_{2}\right)=\operatorname{Prob}\left(B_{t+1}=0 \mid B_{t}>0\right)=.21 \text {. }
$$

The expected value of $B$ for the first year of a war is calculated as the mean value for the five wars since 1889 (for which accurate data on $B$ are available):

${ }^{33}$ War probabilities and the distribution of sizes of wars need not be constant over time, although there is no indication of substantial structural change in the small sample of evidence afforded by the 200 years of U.S. history. (The largest value for the $B$ variable would actually apply to the Civil War-see the notes to table 1.) From the standpoint of constructing the $\overline{g_{t}^{w}}$ variable, shifts in the stochastic structure for wars would essentially be an alternative to the present specification that allows for shifts in spending for a given war structure, as represented by the stochastic variable $\epsilon_{t}$ in eq. (A 1). In the context of output analysis, it is unclear that there would be much empirical difference between these alternatives.

34 The year 1978 is not included in this calculation, although it could have been if peace during 1979 were also included. War years are taken to be 1775-83, 1812-15, $1846-48,1861-65,1898,1917-18,1941-45,1950-53$, and 1964-72. There may be some objection to starting the sample just before a war (which is not independent of the start of U.S. data), but the results are not highly sensitive to this choice.

3.5 The probability $p_{2}$ refers to the existence of war during at least part of a year following a period of war during at least part of the previous year.

36 This calculation pertains to the existence of peace over the entire year $t+1$, conditional on war during at least part of year $t$. 
TABLE A 1

Parameter Values for Expected Casualty Rates

\begin{tabular}{lcc}
\hline \hline$\rho$ & $\mu_{0}$ & $\mu_{1}$ \\
\hline .01 & 1.95 & 2.33 \\
.02 & .94 & 2.26 \\
.05 & .35 & 2.06 \\
.10 & .16 & 1.80 \\
.25 & .051 & 1.30 \\
\hline
\end{tabular}

$$
\begin{aligned}
\bar{B} & \equiv E\left(B_{t+1} \mid B_{t+1}>0, B_{t}=0\right) \\
& =\frac{1}{5}(.005+.23+.004+.071+.001)=.062
\end{aligned}
$$

Since war could break out at any time during the year, the annualized value of $E B_{t+1}$, denoted by $\tilde{B}^{A}$, would be roughly twice the above figure-that is, $\tilde{B}^{A} \approx$ .124 .

Finally, when $B_{t+1}$ and $B_{t}$ are both positive, the conditional expectation for $B_{t}$ is given by

$$
E\left(B_{t+1} \mid B_{t+1}>0, B_{t}>0\right)=\theta_{0}+\theta_{1} B_{t}^{A},
$$

where $B_{t}^{A}$ is the current casualty rate expressed at an annual rate if hostilities applied only to a fraction of year $t$. The parameter $\theta_{1}$ is based on the assumption (not refuted by the small sample of U.S. data) that wars tend neither to grow nor to contract over time, except that war may end at some time during year $t+1$ as governed by the parameter $p_{2}$. Accordingly, $\theta_{1} \approx 1$ $-1 / 2\left(1-p_{2}\right)=.90$. The parameter $\theta_{0}$ is set so that the value of the $\Psi_{t}$ variable, which appears in equation (A6), converges to the value associated with $B_{t+2}=$ 0 as $B_{t+2} \rightarrow 0$ (which essentially recognizes that a new war may break out next year, even if one is already going on). The value of $\theta_{0}$ turns out to be $\theta_{0} \approx p_{1} \bar{B}^{A}$ $=.007$. Accordingly, I use the relation

$$
E\left(B_{t+1} \mid B_{t+1}>0, B_{t}>0\right)=.007+.90 B_{t}^{A} .
$$

Equations (A7)-(A10) allow calculation of the relevant expectation of $\mathrm{fu}$ ture casualty rates, which appears in equation (A6), $\Psi_{t} \equiv \sum_{i=1}^{\infty} E B_{t+i+2} /(1+\rho)^{i}$, conditional on observation of $B$ through $B_{t+2}$ and for a given value of the discount rate $\rho$. The result takes the form

$$
\Psi_{t}=\mu_{0}+\mu_{1} B_{t+2}^{A},
$$

where $\mu_{0}$ and $\mu_{1}$ can be determined as functions of the $\rho$ parameter. ${ }^{37}$ Specifically, these coefficients for selected values of $\rho$ can be seen in table A 1 . Since $\rho$ corresponds to the difference between the real rate of return and the real growth rate, the values of the $\mu$ coefficients corresponding to the lower

${ }^{37}$ The general formulae are:

$$
\begin{aligned}
\mu_{0}= & {\left[\tilde{B} p_{1}\left(1-p_{2}\right)\left(1+\rho+p_{2} \theta_{1}\right)\right.} \\
& \left.+p_{2} \theta_{0}(1+\rho)\left(\rho+p_{1}\right)\right] /\left[\rho\left(1+\rho+p_{1}-p_{2}\right)\left(1+\rho-p_{2} \theta_{1}\right)\right], \\
\mu_{1}= & p_{2} \theta_{1} /\left(1+\rho-p_{2} \theta_{1}\right) .
\end{aligned}
$$


values of $\rho$ would seem to be most pertinent. The empirical results that are reported in the text use the value $\rho=.02$ per year.

The combination of equation (A11) with equations (A5) and (A6) allows calculation of the perceived permanent government purchases ratio, $\overline{g_{t}^{w}}$, as a function of the variables $\left(g_{t}^{w}, k_{t-1}^{w}, B_{t-3}, \ldots, B_{t+2}\right)$ and the parameters $\left(\rho, \gamma, \alpha_{0}\right.$, $\alpha_{1}, \alpha_{2}, \alpha_{3}, a_{1}, a_{2}$ ), where $\rho$ is the net real discount rate, $\gamma$ measures the reaction of current defense purchases to existing capital stock, and the $\alpha$ 's and $a$ 's describe the effect of the array of $B$ variables on defense purchases. The results are therefore expressed in terms of the general form of equation (6) in the text. Other coefficients that appear in the analysis $\left(\delta^{\prime}, b, p_{1}, p_{2}, \tilde{B}\right.$-see, e.g., the expressions contained in n. 37 above) are treated as fixed at the values: $\delta^{\prime}=.16$ per year, $b=.34, p_{1}=.06, p_{2}=.79$, and $\tilde{B}=.062$.

\section{References}

Bailey, Martin J. National Income and the Price Level: A Study in Macroeconomic Theory. 2d ed. New York: McGraw-Hill, 1971.

Barro, Robert J. "Public Debt and Taxes." In Federal Tax Reform: Myths and Realities, edited by Michael Boskin. San Francisco: Inst. Contemporary Studies, 1978.

$\rightarrow-$. "On the Determination of the Public Debt." J.P.E. 87, no. 5, pt. 1 (October 1979): 940-71.

- "A Capital Market in an Equilibrium Business Cycle Model." Econometrica 48 (September 1980): 1393-1417. (a)

- "Federal Deficit Policy and the Effects of Public Debt Shocks." J. Money, Credit and Banking 12, no. 4, pt. 2 (November 1980): 747-62. (b)

-. "Intertemporal Substitution and the Business Cycle." CarnegieRochester Conference Series on Public Policy 14 (Spring 1981): 237-68. (a)

- "Unanticipated Money Growth and Economic Activity in the United

States." In Money, Expectations, and Business Cycles: Essays in Macroeconomics, by Robert J. Barro. New York: Academic Press, 1981. (b)

Benjamin, Daniel K., and Kochin, Levis A. "A Theory of State and Local Government Debt." Unpublished paper, Univ. Washington, 1978.

Hall, Robert E. "Labor Supply and Aggregate Fluctuations." CarnegieRochester Conference Series on Public Policy 12 (Spring 1980): 7-33.

Kendrick, John W. Productivity Trends in the United States. Princeton, N.J.: Princeton Univ. Press (for Nat. Bur. Econ. Res.), 1961.

- The Formation and Stocks of Total Capital. New York: Columbia Univ. Press (for Nat. Bur. Econ. Res.), 1976.

Kydland, Finn E., and Prescott, Edward C. "Rules Rather than Discretion: The Inconsistency of Optimal Plans." J.P.E. 85, no. 3 (June 1977): 473-91.

- "A Competitive Theory of Fluctuations and the Feasibility and Desirability of Stabilization Policy." In Rational Expectations and Economic Policy, edited by Stanley Fischer. Chicago: Univ. Chicago Press (for Nat. Bur. Econ. Res.), 1980.

$\rightarrow$ Kuznets, Simon. "Discussion of the New Department of Commerce Income Series: National Income: A New Version." Rev. Econ. and Statis. 30 (August 1948): 151-79.

$\rightarrow$ Lucas, Robert E., Jr. "An Equilibrium Model of the Business Cycle.” J.P.E. 83, no. 6 (December 1975): 1113-44.

$\rightarrow$ Lucas, Robert E., Jr., and Rapping, Leonard A. "Real Wages, Employment, and Inflation." J.P.E. 77, no. 5 (September/October 1969): 721-54. 
Musgrave, Richard A. The Theory of Public Finance: Study in Public Economy. New York: McGraw-Hill, 1959.

Plosser, Charles I., and Schwert, G. William. "Money, Income, and Sunspots: Measuring Economic Relationships and the Effects of Differencing." $J$. Monetary Econ. 4 (November 1978): 637-60.

Samuelson, Paul A. "The Pure Theory of Public Expenditure." Rev. Econ. and Statis. 36 (November 1954): 387-89.

$\rightarrow$ Thompson, Earl A. "Taxation and National Defense." J.P.E. 82, no. 4 (July/ August 1974): 755-82. 